\title{
PREVALENCE OF ECTOCILIATE DISEASES IN CULTURED FRESHWATER FISH AT KAFR EL-SHEIKH GOVERNORATE
}

\author{
Mohamed S.M. Gado ${ }^{1}$, Nadia B. Mahfouz, ${ }^{1}$ Mohamed T. Shehab El-Din ${ }^{2}$ \\ and Hend A.M. El-Saftawy ${ }^{2}$ \\ ${ }^{1}$ Fish Diseases and Management Dept., Fac. Vet. Med., Kafrelsheikh Univ . \\ 2. Central Laboratory for Aquaculture Research Abbassa, Sharkia, \\ Sakha Aquaculture Research Unit.
}

\begin{abstract}
A total number of 1600 cultured freshwater fish species; Oreochromis niloticus (O. niloticus), Clarias garepinus (C. garepinus), Ceprinus carpio (common carp) and Mugil cephalus, 100 of each fish species per season with different weights and sizes, were examined for the presence of common ciliated protozoal diseases affecting the cultured freshwater fish;which revealed the presence of (Trichodina, Chilidonella, Ichthyophthirius multifillis, Apizoma, Epistylis), in relation to their seasonal incidence. The clinical signs and postmortem lesions of diseased fish were recorded. Some heamatological and serum biochemical parameters of diseased fish were reported. The histopathological alterations in skin, gills and fins of naturally diseased fish with ectociliates were also reported.
\end{abstract}

\section{INTRODUCTION}

Kafr El-Sheikh governorate, has the highest fish production rate all over Egypt from either owned or temporarily private fish farms; 109,725 and 214,900 MT per 31,350 and 61,400 acres (feddan), respectively (Fish Statistics Year Book, 2012). 
Generally, in Egypt at Kafr El-Sheikh governorate in particular; the water supply of the fish farms is mainly the agriculture drainage water that may be sometimes mixed with sewage wastes; which is considered an ecological stress and predisposing factors paving the way for the prevalence of either external or internal parasitic diseases in cultured fishes.

Fish parasites producing diseases has a great effect on fish productivity through mortalities, slow growth rates as well as low grade quality meat (Limit, 1991 and Floyed, 2003), which might be refused by the consumers, which in turn have low economic impact.

Pathogenicity of fish ectoparasites affecting the skin and gills of cultured freshwater fish is very important because of its severe skin damage (Otify et al., 1991).

The present work was planned to study the most common ciliated protozoal diseases affecting the cultured freshwater fishes in Kafr ElSheikh governorate.

\section{MATERIALS AND METHODS}

\section{Fish samples:}

A total number of 1600 cultured freshwater fish species; $O$. niloticus, C. garepinus, C. carpio and Mugil cephalus, 100 of each fish species per season with different weights and sizes were collected alive from different fish farms at Sedi-Salem district, in Kafr El-Sheikh governorate, and transferred according to Hetrick (1983), and holded in prepared glass aquaria in the laboratory of fish diseases and managmenet dept., Faculty of Veterinary Medicine, Kafrelsheikh University and the Central Laboratory of AquaCulture Research, Sakha Unite. 


\section{Aquaria:}

Full equipped glass aquaria were used for holding fish throughout the period of examination according to the method described by Innes (1966).

\section{Clinical signs and post-mortum examinations:}

The live collected fishes held in glass aquaria were immediately examined grossly by naked eye and with the aid of magnification lens to determine the abnormal changes on the external body surface, e.g. skin discoloration, fins and gills errosions, swellings, hemorrhages, ulcerations and exophthalmia .... etc. The examinations were carried out according to the methods described by Lucky (1977) and Woo (1995).

\section{Parasitological examinations:}

\subsection{Examination of skin and fins:}

Direct smears were obtained from the two lateral sides of the skin, as well as the fins. The skin and fin scrapings were mixed with few drops of distilled water and examined microscopically, using both low and high magnification powers according to Lucky (1977).

\subsection{Examination of gills:}

The gill arch and filaments were scraped; a few drops of distilled water were added to obtain a uniform distribution under the entire cover slip; and examined under the microscope according to Lucky (1977).

\subsection{Mounting and fixation of ciliates:}

Gills were examined immediately to avoid the disintegration or escape of the external protozoa. Smears for protozoal examination were taken very thin and allowed to dry for 2-3 minutes and fixed with 
absolute methyl alcohol for 5 minutes. The fixed slides were then stained with freshly diluted Giemsa stain for 30-45 minutes and impregnated in dense canda balsam then left to dry in the incubator at $37 \pm 1 \mathrm{c}$ for 24 hours for driving any bubbles. Examinations of both fresh and stained smears were carried out under low, high objectives and oil immersion lenses according to the methods adopted by (Lucky, 1977 and Kabata 1985).

\subsection{Identification of collected ciliates:}

The collected parasites were identified according to the identification keys of Blanchard (1885), Faure-Fermiet (1905), Paperna (1996), El-Tantawy and El-Sherbiny (2010a,b).

\section{Hematological and serum biochemical examinations:}

The total count of red blood cells and white blood cells, as well as the packed cell volume (PCV) were determined according to Stoskopf (1993). The Haemoglobin content was determined by the Sahli's method as well as the differential leucocytic count films were prepared and stained according to Lucky (1977). The percentage and absolute value for each type of leucocytic cells were calculated according to Schalm (1986).

The total serum proteins as well as serum albumin were determined colorimetrically at the wave length, $450 \mathrm{~nm}$ and $630 \mathrm{~nm}$, respectively according to Peters (1970). Serum globulin was calculated acc. to Doumas and Biggs (1972). Albumin globulins ratio was determined according to Coles (1974). The serum alkaline phosphatase was determined colorimetrically at the wave length $510 \mathrm{~nm}$ according to Kind and King (1954). Serum asparatate aminotransferase (S AST) and serum alanine 
aminotransferase (S.ALT) were determined colorimetrically at the wave length $546 \mathrm{~nm}$, according to Reitman and Frankel (1957). Phagocytic activity and phagocytic index were determined according to Kawahara et al. (1991).

\section{Histopathological examination:}

From the sacrificed naturally infected Oreochromis niloticus, Clarias garepinus, Ceprinus carpio and Mugil cephalus, tissue specimens were taken from the infected organs (gills, skin, and fins) fixed in $10 \%$ buffered formaline saline and dehydrated through different concentrations of ethyl alcohol, treated with xylol then blocked in paraffin boxes, according to Roberts (1978). Sections of 4-5 microns thickness were mounted on cleaned slides, stained by Haematoxyline and Eosin technique, (Carleton et al., 1967).

\section{RESULTS AND DISCUSSION}

\section{Clinical and post mortem examinations:}

The external gross lesions of the naturally ciliate infected fish revealed, emaciation, dark or pale body coloration, excessive amounts of mucous on the external body surface, Scale detachment (Fig. 1), hemorrhages, wounds and ulcers (Fig. 2 and 3), were also present, (ElKhatib, 2003 and Abboud, 2001), which may be contributed to the continuous irritation of ciliated protozoa on the fish, while the mucous was released to relief the irritating inflammatory reaction (Khalil, 2010; Marrzouk, 2002 and Mohammed et al., 2004). Exthophthalmia and corneal opacity (Fig. 4) was also reported (Abd El-Aal, 2002).

On autopsy of naturally ciliate infected fish; the liver and spleen may be pale anemic or dark congested in coloration with distended gallbladder. The stomach was bulged with food and the intestine was 
congested and containing mucoid secretion as well as abdominal dropsy, (Fig. 5), (Rawia Adway, 2000; Ibtsam, 2004 and Osman, 2005).

\section{Parasitological examination:}

Microscopic smears were taken from gills, skin and fins of examined fishes, revealed some ciliated protozoans. Trichodina, has an adhesive discs with flat lateral projections. The upper view is round, while the lateral view is either dish when standing or bell-shaped when free swimming in the water, (Fig.6).

Chilodonella sp., appeared as large, flattened, ovoid shaped or heart shaped ciliates with bands of cilia along the long axis of organisms. A single oval to round macronucleus as well as round micronucleus, (Fig.7). Icthyophthirius multifilliis, has large round to oval shape ciliated parasites from 0.5 up to $1 \mathrm{~mm}$ in diameter. They have macronucleus embedded in the protoplasm and characterized by a horseshoe, cresented or C-shape. The micronucleus is spherical, very small, (Fig.8).

Apisoma sp.,has a vase-like shape and oral ciliated parasites. The parasite have a pyriform nucleus and small scopula, (Fig.9). Epistylis sp., is a sessile, ciliated protozoans that propagates as colonies at the end of non-contractile stalks,(Fig.10).

\section{Incidences of fish ciliates among different fish species and seasons:}

In general, the incidence of different ciliated fish protozoans among different fish species; O. niloticus, $M$. cephalus, $C$. garipenus and $C$. carpio; in different seasons cleared that, the higher incidence were observed in summer followed by spring then autumn and the lowest incidence in winter season (Table 1). 
The highest parasitic infection level of Ich. was observed in C.garipenus in summer season. The highest prevalence of Trichodina was observed in C.carpio in winter season. While the highest incidence of Chilodonella was recorded in C.carpio and C.garipenus in spring season. As well as, the highest prevalence of Apizoma was reported in C.garipenus in both summer and autumn season. The highest infection level of Epistylis was recorded in C.garipenus in autumn season, (tables 2, 34 and 5).

Tawfik (2005) recorded a higher prevalence of ciliated protozoans in winter; rather than a higher prevalence of spring and autumn that reported by Hoffman (1987), Hassan (1992), El-Khatib (1993), Osman (2001) and Rashed (2013). Also, the results are somewhat similar to those reported by Jeronimo et al. (2011) where a $100 \%$ prevalence of Epistylis magna during winter season. On contrast, Abd El-Gawad (2004) recorded a highest prevalence of Apizomiasis in $C$. garipenus in spring $(4.88 \%)$ and not detected in other seasons in Sharkia province; these contraversery may be due to the differences in culture system and environmental farm conditions (Yatabe et al., 2011).

Badran et al. (1996) reported that Apizomiasis, Epistylosis and Trichodinosis had a higher incidence (4.5\%) in spring season as well as, Noor El-Deen (2000) for trichodinolosis only. Babiker (2013) mentioned that there was no significant difference between $O$. niloticus and $C$. garipenus for protozoal parasitic infection in both cultured and natural environments. On the other hand, the results of the present study, were in contrary with the findings of both El-Sayed (1993) and El-Khatib (1993) that mentioned, the highest percentage of ciliated protozoal infections were observed in $O$. niloticus followed by $C$. garipenus; in spring. 
Also, Abd Elmegiud (1989), Eissa (2002) and Rashed (2013) recorded that Ichthyophthirius multifiliis, has a higher prevalence in $C$. carpio in summer and spring seasons. Although, Rashed (2007) found that Ichthyophthirius multifiliis, reach the maximum rate of infection during winter season in Kafr El-Sheikh governorate.

Hassan (1992), El-Khatib (2003), Ibtsam (2004), Awad (2007) and Doaa El-Moghazy (2008) reported that the incidence of fish ciliated protozoans in Egypt; highly prevalence mainly in summer season, because of the higher temperature in summer was suitable for parasitic reproduction. On the other side, neither Paperna and Vanas (1983) nor Jerônimo et al. (2011) mentioned that the higher incidence in summer but, was confirmed in cooler seasons; these differences may be attributed to different geographic regions, water sources and fish species (Eissa, 2002 and Saleh and El-Nobi, 2003). Bassiony (2002) mentioned that the most important protozoan ciliate infections occur in autumn. Doaa ElMoghazy (2008) and Abu Elkheir (2006) reported that the lower incidence of Apizomiasis in C. garipenus at Sharkia, Dakahlia and Kafr El-Sheikh governorates, was in autumn season.

Mohammed (1996) reported that O. niloticus infected with Epistylosis in Suez canal area, had the lower infection rate during autumn season; Somewhat similar to Abd El-Khalek (1998) that recorded the same results in Beni-Suef province and Gharib (2005) in Kafr El-Sheikh province, Younis (1999) recorded the highest prevalence of Epistylosis in O. niloticus at Beni-Suef area, in winter season; rather than that recorded in the present study (autumn). 


\section{Haematological investigations on protozoan infected fish:}

The Haematological investigations of (RBCs, WBCs, Hb, PCV, DLC) on protozoan infected fish were summarized in (tables 6-14). Murad and Mostafa (1988); Ibtsam (2004) and Tavares-Dias et al. (2002) reported a lower erythrocytic counts,low haematocrite and haemoglobin readings and a higher leucocytic count in catfish; although Azevedo et al. (2006) stated that the total number of erythrocytes and leucocytes, didn't show relation with the ecto-parasites infections. Hines and Spira (1973) reported that there no any alterations in WBCs and leukocyte count in the course of Ichthyophthirius multifiliis in common carp is dynamic and probably related to its severity.

Liu et al. (2004) mentioned that Ichthyophthirius multifiliis, render fish very susceptible to other fish pathogens which may be reflected in fluctuations of various haematogram components. Alvarez Pellitero (2008) mentioned that ciliated protozoa, may modulate inflammatory reactions in fish. Nadia Mahfouz (1997) reported that the ciliate parasites stimulate granulocytes synthesis, that disturb the values of differential leucocytic counts. El-Seify et al. (2003) reported an increase in differential leucocytic counts in infected fish except for eosinophiles, which are less significantly changed. Although, Morad and Mostafa (1998) recorded an increase in eosinophils and monocytes.

\section{Blood serum analysis of protozoans infected fish:-}

The total serum proteins, albumin, globulins, A/G ratio, ALT, AST and ALP of protozoan infected fish are summarized in tables (15 -21). 
El-Seify et al. (2003) recorded that total proteins, globulins and albnumin were decreased in ciliated infected $O$. niloticus. Nadia Mahfouz (1997) mentioned that total protein and albumin had significantly decreased in infected fish with ciliated protozoa; while, the globulins were higher inspite of, lower A/G ratio. Although Awad (1992) recorded that the total serum proteins didn't show any significant changes between naturally infected and apparently healthy fish.

The obtained enzymatic serum values (AST, ALP and ALT) in the present study are somewhat higher than that detected by Bassiony (2002); Osman (2005); Ibtsam (2004) and Rashed (2013).

\section{The phagocytic activity and phagocytic index :}

Results of phagocytic activity and index are summarized in tables (22 and 23).

This increase in the PA and PI values were also reported by Stosik (2002), Kollner et al. (2004), Tavares-Dias (2007) and Rashed (2013). Also, Tavares-Dias (2002) mentioned that Ichthyophthiriasis in Nile tilapia showed an increase in phagocytic activity. Coles (1986) stated that the increasing phagocytic activity was attributed to the increasing lymphocytic numbers.

\section{Histopathological findings:}

Alterations caused by ciliates on gills of examined fishes showed many degenerative changes in both primary and secondary gill lamellae in the form of hyperplasia of epithelial cell proliferations, especially in 
the secondary gill lamellae, In addition to leucocytic cell infiltrations. Worthy, this alterations were severe in Trichodinosis. In addition to congestion,eosinophilic infilteration and granulosis in the gill arch and gill lamellae, (Fig.11). This picture was also reported by Roberts (2012), Osman (2001) and Noor El-Deen et al. (2014). The pathological gill alterations of Chilodonelosis may be attributed to their nourishing action on the cell of the gill lamellae, reproduce rapidly leading to destruction of the gills.

A multifocal coalescing areas of degeneration, epithelial necrosis and ulceration of the skin, Indeed, progressive cellular destruction and hyperplasia of epithelial cells especially the mucous cells. This alterations were evenly distributed due to the infections of Apizoma, Epistylis, Chilodonella and Ichthyophthirius multifiliis, FAO (2013) and De Padua et al. (2014). The skin ulcers and gill damage, might cause a portal of entry to secondary infections.The epithelial hyperplasia, mucous cell proliferations and necrosis in the gill tissues might limit the osmoregulatory gas and ion exchanges in the fish leading to metabolic disturbances being lethal to the host, (Fig.12-17).

\section{CONCLUSION}

The ecological stress factors, like the organic matter load, ammonia, defficiency of oxygen, extravagance use of fertilizers as well as the other relevants, in the water environment play an important role, in the onset and spread of the parasitic diseases notably, the ectoparasitic ones, therefore special care should be adopted for the water environment to reduce aforementioned predisposing factors. 
Mohamed S.M. Gado et., al.
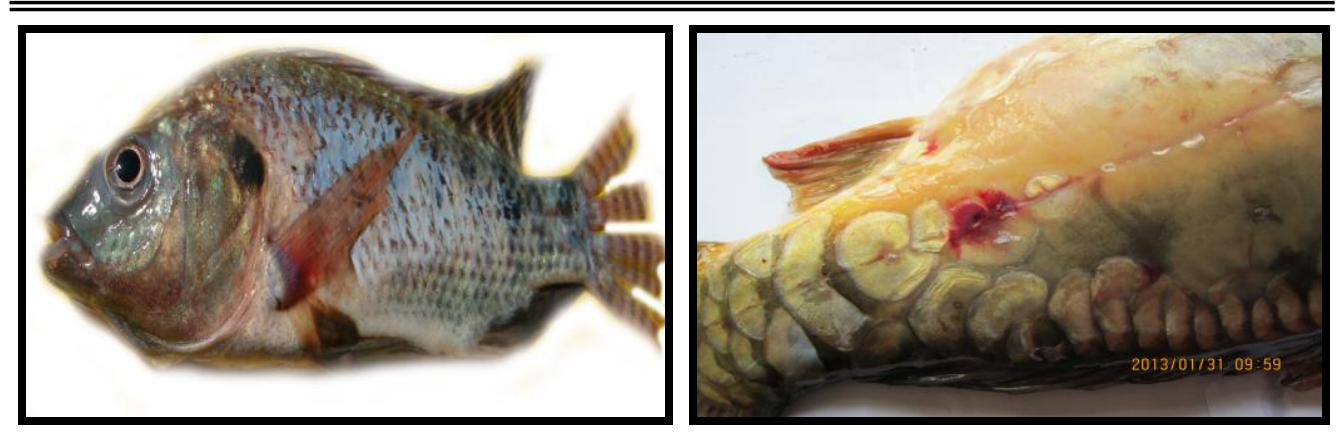

Fig. (1): O. niloticus with a large area of Fig. (2):C.carpio showing a haemorrhagic scale detachment at the lateral ulder at the caudal peduncle side and caudal fin erosion
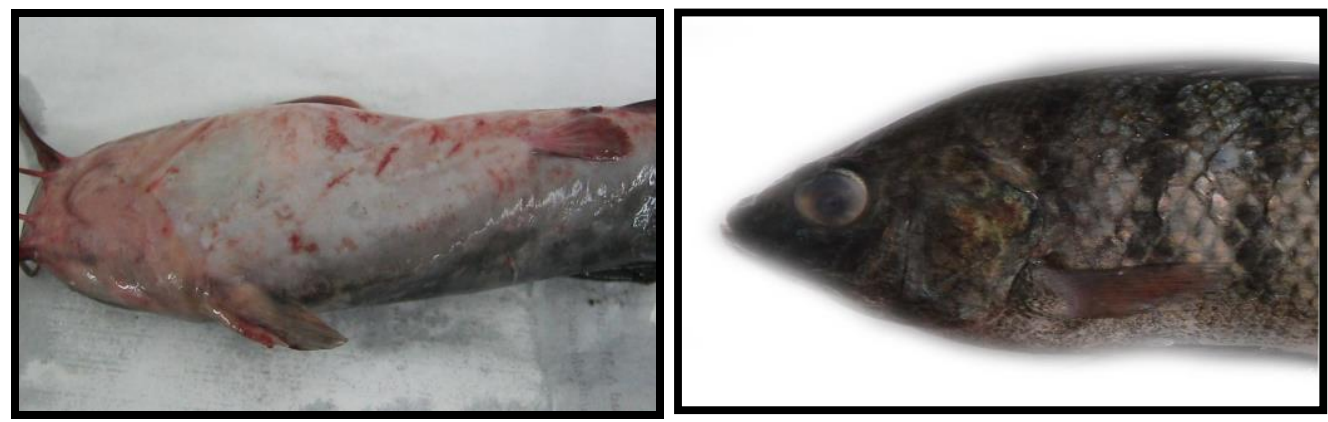

Fig. (3): C. garipenus showing scattered Fig. (4): O. niloticus with blurring eye, haemorrhagic ulcers and petications on the ventral scale detachment and skin depigmentation aspects of head and abdomen

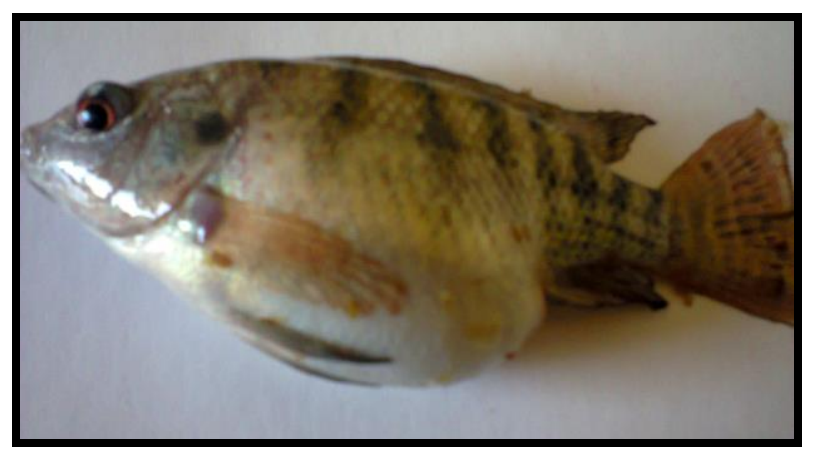

Fig. (5): O. niloticus with severe abdominal dropsy and exthophthalmia

\section{(Plates of infected fishes)}

$\overline{\overline{\text { Kafrelsheikh Vet. Med. J. Vol. } 13 \text { No. } 1 \text { (2015) }}}$ 
Prevalence Of Ectociliate Diseases In Cultured ...

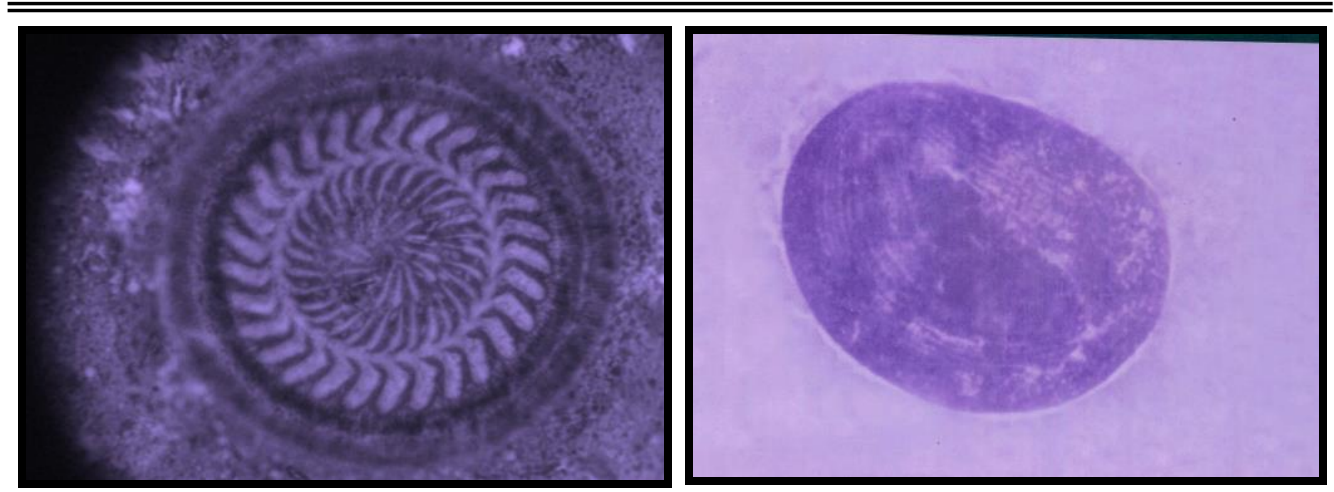

Fig. (6):Trichodina centrostriagata isolated Fig.(7):Chilodonella hexasticha isolated from gills of $O$. niloticus (X400) from O. niloticus (X400)
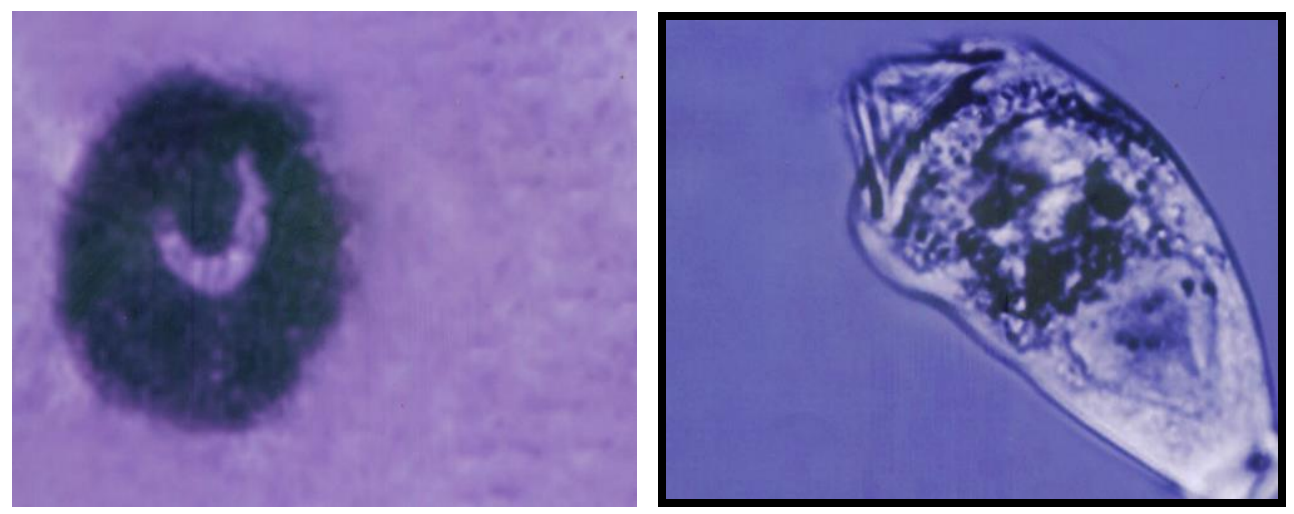

Fig. (8): Ichthyophthirius multifiliis Fig. (9): Apisoma gasterostei isolated isolated from skin of $C$. from skin of C. carpio (X200) garipenus (X200).

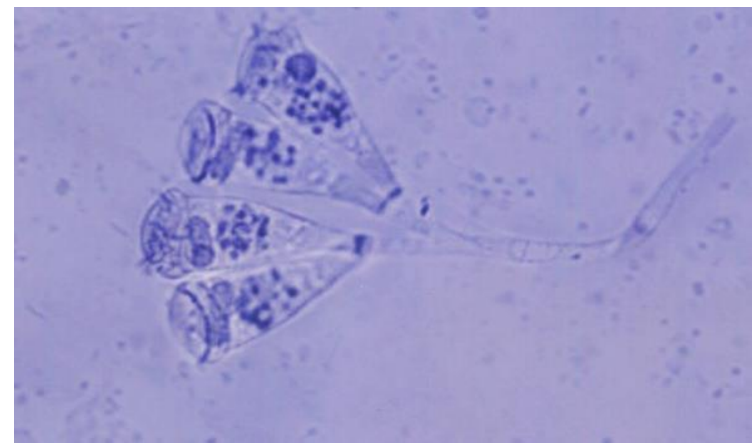

Fig. (10): Epistylis isolated from gills of M. cephalus (X200)

(Plates of isolated parasites)

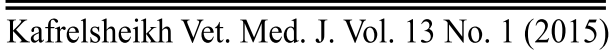


Mohamed S.M. Gado et., al.
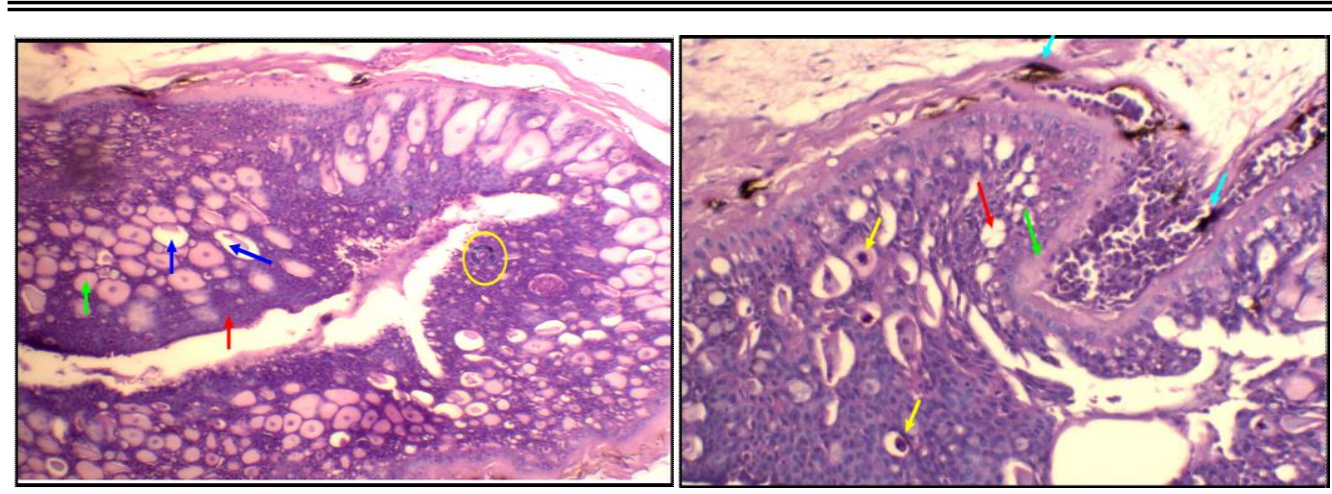

Fig. (11): Skin of M. cephalus infected Fig. (12): Skin of M. cephalus infected with with Trichodina (yellow circle) showing dermal odema (green arrow), numerous epidermal vacules (blue arrow) and inflammatory cell infiltration (red arrow) (X100 H \& E). Apizoma (yellow arrow) showing, multifocal areas of hydropic degeneration(redarrow), progressive cellular destruction, melanosis (blue arrow) and loss of cell architecture (green arrow) $(\mathrm{H}$ \& E X200)
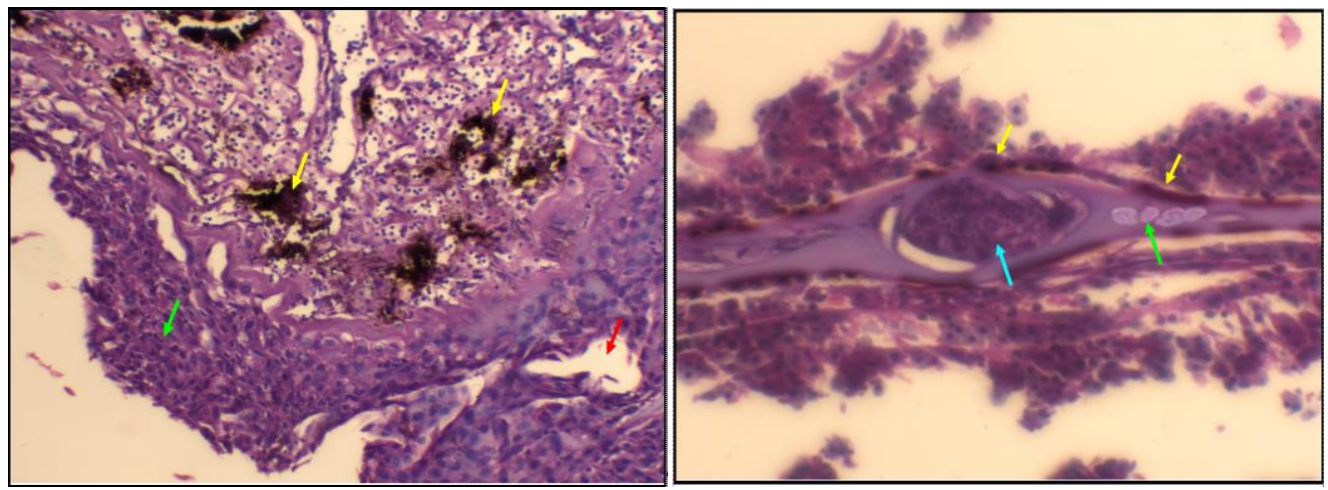

Fig. (13): Skin of O. niloticus infected with Epistylis showing mucus and cub cell proliferations (green arrow), multifocal areas and degeneration (red arrow) and inflammatory cell infiltration (yellow arrow) (H \& E X100)

Fig. (14): Skin of $O$. niloticus infected with Chilodonella (blue arrow) showing accumulations of melanophores (yellow arrow) and epidermal invasion of the activated cub cells (green arrow) (H \& E X100).

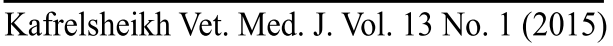




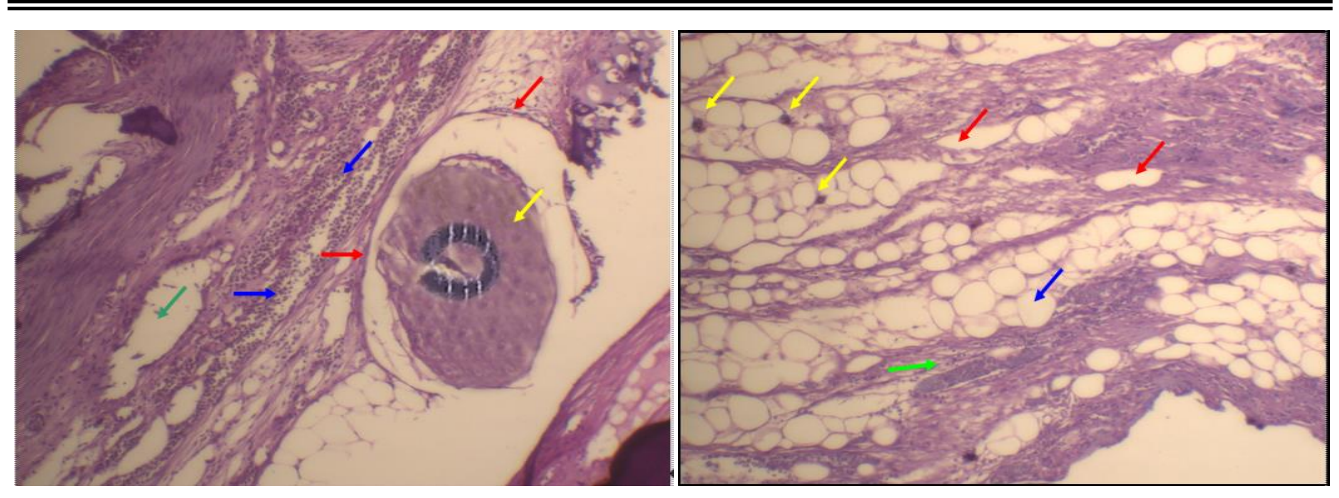

Fig. (15): Skin of $C$. garipenus infected Fig. (16): Fin of $O$. niloticus embedded with Ich. showing the horse shaped nucleus (yellow arrow), with Ich trophans (yellow mucous cell proliferation (blue arrow), hyperplasia, hydropic degeneration (green arrow) and necrosis with ulceration around the parasitic attachment (red arrow) (H \& E X200) arrow) and showing erosions (red arrow), epidermal separations (green arrow), shrinkage, atrophy and dermal vaculation (blue arrow) ( $\mathrm{H} \& \mathrm{E}$ $\mathrm{X} 100)$

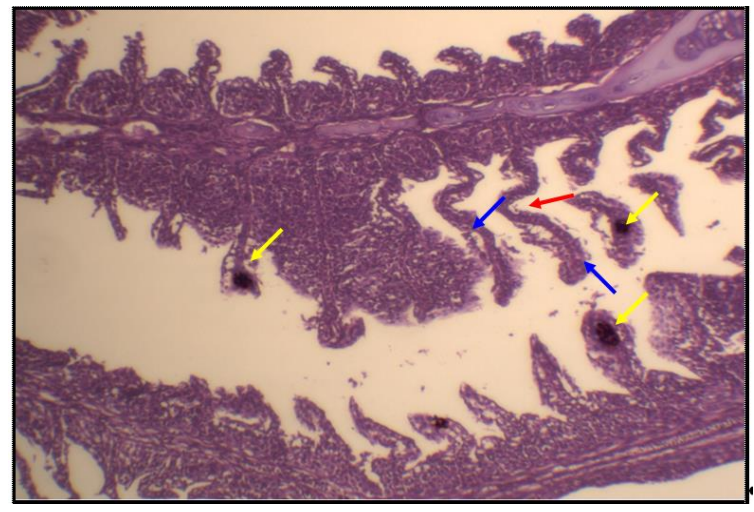

Fig. (25): Gills of C. garipenus embedded with trophont stages of Ich (yellow arrow) and showing elongation of secondary lamellae (blue arrow) and interlamellar hyperplasia (red arrow) (H \& E X200)

\section{Plates of Histopathological findings}

$\overline{\overline{\text { Kafrelsheikh Vet. Med. J. Vol. } 13 \text { No. } 1 \text { (2015) }}}$ 
Mohamed S.M. Gado et., al.

Table (1): Incidence of infected fish species in different seasons.

\begin{tabular}{|c|c|c|c|c|c|}
\hline \multirow{2}{*}{ Fish species } & \multirow{2}{*}{$\begin{array}{c}\text { No. samples per } \\
\text { season }\end{array}$} & \multicolumn{4}{|c|}{ Infection percent per season } \\
\hline & & Winter & Spring & Summer & Autumn \\
\hline O. niloticus & 100 & 40 & 60 & 66 & 55 \\
\hline M. cephalus & 100 & 45 & 65 & 71 & 61 \\
\hline C. garepinus & 100 & 80 & 77 & 80 & 77 \\
\hline C. carpio & 100 & 60 & 75 & 75 & 66 \\
\hline
\end{tabular}

Table (2): Incidence of ciliated protozoan diseases among different fish species in winter season.

\begin{tabular}{|c|c|c|c|c|c|c|c|c|}
\hline \multirow[b]{2}{*}{ Fish species } & \multirow{2}{*}{$\begin{array}{c}\text { No. } \\
\text { samples }\end{array}$} & \multirow{2}{*}{$\begin{array}{c}\text { No. } \\
\text { infected } \\
\text { samples }\end{array}$} & \multicolumn{6}{|c|}{ Infection percent } \\
\hline & & & $\begin{array}{c}\text { I. } \\
\text { multifilis }\end{array}$ & Trichodina & Chilodenilla & Apizoma & Epistyles & \begin{tabular}{|c|} 
Mixed \\
infections
\end{tabular} \\
\hline O. niloticus & 100 & 40 & 15 & 8 & 4 & 4 & 5 & 4 \\
\hline M. cephalus & 100 & 45 & 16 & 8 & 5 & 5 & 6 & 5 \\
\hline C. garepinus & 100 & 80 & 20 & 15 & 10 & 3 & 4 & 28 \\
\hline C. carpio & 100 & 60 & 20 & 17 & 8 & 4 & 4 & 7 \\
\hline
\end{tabular}

Table (3): Incidence of ciliated protozoan diseases among different fish species in spring season.

\begin{tabular}{|c|c|c|c|c|c|c|c|c|}
\hline \multirow[b]{2}{*}{ Fish species } & \multirow{2}{*}{$\begin{array}{c}\text { No. } \\
\text { samples }\end{array}$} & \multirow{2}{*}{$\begin{array}{c}\text { No. } \\
\text { infected } \\
\text { samples }\end{array}$} & \multicolumn{6}{|c|}{ Infection percent } \\
\hline & & & $\begin{array}{c}\text { I. } \\
\text { multifillus }\end{array}$ & Trichodina & Chilodenilla & Apizoma & Epistyles & \begin{tabular}{|c|} 
Mixed \\
infections
\end{tabular} \\
\hline O. niloticus & 100 & 60 & 18 & 12 & 6 & 7 & 4 & 13 \\
\hline M. cepohalus & 100 & 65 & 19 & 13 & 7 & 8 & 7 & 11 \\
\hline C. garepinus & 100 & 77 & 25 & 14 & 14 & 10 & 12 & 2 \\
\hline C. carpio & 100 & 75 & 22 & 13 & 14 & 6 & 4 & 16 \\
\hline
\end{tabular}

Table (4): Incidence of ciliated protozoan diseases among different fish species in summer season.

\begin{tabular}{|c|c|c|c|c|c|c|c|c|}
\hline \multirow[b]{2}{*}{ Fish species } & \multirow{2}{*}{$\begin{array}{c}\text { No. } \\
\text { samples }\end{array}$} & \multirow{2}{*}{$\begin{array}{c}\text { No. } \\
\text { infected } \\
\text { samples }\end{array}$} & \multicolumn{6}{|c|}{ Incidence percent } \\
\hline & & & $\begin{array}{c}\text { I. } \\
\text { multifillus }\end{array}$ & Trichodina & Chilodenilla & Apizoma & Epistyles & $\begin{array}{c}\text { Mixed } \\
\text { infections }\end{array}$ \\
\hline O. niloticus & 100 & 66 & 15 & 14 & 12 & 6 & 9 & 10 \\
\hline M. cephalus & 100 & 71 & 14 & 17 & 11 & 9 & 11 & 9 \\
\hline C. garepinus & 100 & 80 & 28 & 10 & 10 & 12 & 10 & 10 \\
\hline C. carpio & 100 & 75 & 21 & 13 & 11 & 8 & 7 & 15 \\
\hline
\end{tabular}

Kafrelsheikh Vet. Med. J. Vol. 13 No. 1 (2015) 
Prevalence Of Ectociliate Diseases In Cultured ...

Table (5): Incidence of parasitic diseases among different fish species in Autumn season.

\begin{tabular}{|c|c|c|c|c|c|c|c|c|}
\hline \multirow[b]{2}{*}{ Fish species } & \multirow{2}{*}{$\begin{array}{c}\text { No. } \\
\text { samples }\end{array}$} & \multirow{2}{*}{$\begin{array}{c}\text { No. } \\
\text { infected } \\
\text { samples }\end{array}$} & \multicolumn{6}{|c|}{ Incidence percent } \\
\hline & & & $\begin{array}{c}\text { I. } \\
\text { multifillus }\end{array}$ & Trichodina & Chilodenilla & Apizoma & Epistyles & $\begin{array}{c}\text { Mixed } \\
\text { infections }\end{array}$ \\
\hline O. niloticus & 100 & 55 & 10 & 5 & 4 & 5 & 5 & 26 \\
\hline M. cephalus & 100 & 61 & 11 & 6 & 5 & 6 & 6 & 27 \\
\hline C. garepinus & 100 & 77 & 15 & 10 & 11 & 12 & 14 & 15 \\
\hline C. carpio & 100 & 66 & 12 & 7 & 8 & 5 & 12 & 22 \\
\hline
\end{tabular}

Table (6): The erythrothytic count of protozoan infected fish (x $\left.10^{6} \mathrm{~mm}\right)$.

\begin{tabular}{|c|c|c|c|c|c|c|}
\hline Fish species & I. multifillus & Trichodina & Chilodenilla & Apizoma & Epistyles & $\begin{array}{c}\text { Mixed } \\
\text { infections }\end{array}$ \\
\hline O. niloticus & $\begin{array}{c}\text { B } \\
1.20 \pm 0.20\end{array}$ & $\begin{array}{c}\mathrm{C} \\
1.11 \pm 0.10\end{array}$ & $\begin{array}{c}\text { B } \\
1.15 \pm 0.15\end{array}$ & $\begin{array}{c}\mathrm{D} \\
1.19 \pm 0.11\end{array}$ & $\begin{array}{c}\mathrm{C} \\
1.19 \pm 0.11\end{array}$ & $\begin{array}{c}\text { B } \\
1.19 \pm 0.11\end{array}$ \\
\hline M. cephalus & $\begin{array}{c}\text { B } \\
1.21 \pm 0.22\end{array}$ & $\begin{array}{c}\text { B } \\
1.18 \pm 0.11\end{array}$ & $\begin{array}{c}\mathrm{A} \\
1.36 \pm 0.18\end{array}$ & $\begin{array}{c}\mathrm{C} \\
1.25 \pm 0.12\end{array}$ & $\begin{array}{c}\mathrm{C} \\
1.22 \pm 0.13\end{array}$ & $\begin{array}{c}\text { B } \\
1.22 \pm 0.12\end{array}$ \\
\hline C. garepinus & $\begin{array}{c}\mathrm{A} \\
1.40 \pm 0.40\end{array}$ & $\begin{array}{c}\mathrm{A} \\
1.50 \pm 0.50\end{array}$ & $\begin{array}{c}\mathrm{A} \\
1.35 \pm 0.13\end{array}$ & $\begin{array}{c}\mathrm{A} \\
1.40 \pm 0.14\end{array}$ & $\begin{array}{c}\mathrm{A} \\
1.60 \pm 0.16\end{array}$ & $\begin{array}{c}\text { A } \\
1.44 \pm 0.14\end{array}$ \\
\hline C. carpio & $\begin{array}{c}\text { B } \\
1.22 \pm 0.21\end{array}$ & $\begin{array}{c}\text { B } \\
1.20 \pm 0.20\end{array}$ & $\begin{array}{c}\text { B } \\
1.18 \pm 0.18\end{array}$ & $\begin{array}{c}\text { B } \\
1.33 \pm 0.13\end{array}$ & $\begin{array}{c}\text { B } \\
1.40 \pm 0.14\end{array}$ & $\begin{array}{c}\text { B } \\
1.25 \pm 0.12\end{array}$ \\
\hline
\end{tabular}

Means within the same column of different litters are significantly different at $\mathrm{P}<0.01$ ).

Table (7): The leucocytic counts of protozoan infected fish (x $10^{4} / \mathrm{mm}$ ).

\begin{tabular}{|c|c|c|c|c|c|c|}
\hline Fish species & I. multifillus & Trichodina & Chilodenilla & Apizoma & Epistyles & $\begin{array}{c}\text { Mixed } \\
\text { infections }\end{array}$ \\
\hline O. niloticus & $\begin{array}{c}\mathrm{C} \\
2.80 \pm 0.18\end{array}$ & $\begin{array}{c}\mathrm{D} \\
2.44 \pm 0.12\end{array}$ & $\begin{array}{c}\text { C } \\
2.13 \pm 0.13\end{array}$ & $\begin{array}{c}\mathrm{C} \\
2.70 \pm 0.17\end{array}$ & $\begin{array}{c}C \\
2.60 \pm 0.16\end{array}$ & $\begin{array}{c}\mathrm{C} \\
2.90 \pm 0.19\end{array}$ \\
\hline M. cephalus & $\begin{array}{c}C \\
2.85 \pm 0.19\end{array}$ & $\begin{array}{c}\text { C } \\
2.57 \pm 0.12\end{array}$ & $\begin{array}{c}\text { B } \\
2.19 \pm 0.13\end{array}$ & $\begin{array}{c}\mathrm{C} \\
2.75 \pm 0.17\end{array}$ & $\begin{array}{c}\mathrm{C} \\
2.66 \pm 0.16\end{array}$ & $\begin{array}{c}\mathrm{C} \\
2.95 \pm 0.19\end{array}$ \\
\hline C. garepinus & $\begin{array}{c}\text { A } \\
3.99 \pm 0.13\end{array}$ & $\begin{array}{c}\text { A } \\
3.50 \pm 0.13\end{array}$ & $\begin{array}{c}\text { A } \\
3.10 \pm 0.13\end{array}$ & $\begin{array}{c}\mathrm{A} \\
3.91 \pm 0.19\end{array}$ & $\begin{array}{c}\mathrm{A} \\
3.91 \pm 0.19\end{array}$ & $\begin{array}{c}\mathrm{A} \\
3.90 \pm 0.18\end{array}$ \\
\hline C. carpio & $\begin{array}{c}\text { B } \\
2.89 \pm 0.19\end{array}$ & $\begin{array}{c}\text { B } \\
2.84 \pm 0.12\end{array}$ & $\begin{array}{c}\text { B } \\
2.22 \pm 0.12\end{array}$ & $\begin{array}{c}\text { B } \\
2.87 \pm 0.12\end{array}$ & $\begin{array}{c}\text { B } \\
2.81 \pm 0.12\end{array}$ & $\begin{array}{c}\text { B } \\
3.10 \pm 0.22\end{array}$ \\
\hline
\end{tabular}

Means within the same column of different litters are significantly different at $\mathrm{P}<0.01$ ).

$\overline{\text { Kafrelsheikh Vet. Med. J. Vol. } 13 \text { No. } 1 \text { (2015) }}$ 
Table (8): The haemoglobin content of protozoan infected fish.

\begin{tabular}{|c|c|c|c|c|c|c|}
\hline Fish species & I. multifillus & Trichodina & Chilodenilla & Apizoma & Epistyles & $\begin{array}{c}\text { Mixed } \\
\text { infections }\end{array}$ \\
\hline O. niloticus & $\begin{array}{c}C \\
8.20 \pm 0.12\end{array}$ & $\begin{array}{c}\mathrm{C} \\
9.20 \pm 0.19\end{array}$ & $\begin{array}{c}\text { B } \\
8.44 \pm 0.14\end{array}$ & $\begin{array}{c}\mathrm{D} \\
7.90 \pm 0.19\end{array}$ & $\begin{array}{c}\mathrm{D} \\
8.0 \pm 0.18\end{array}$ & $\begin{array}{c}C \\
8.70 \pm 0.17\end{array}$ \\
\hline M. cephalus & $\begin{array}{c}\mathrm{C} \\
8.23 \pm 0.14\end{array}$ & $\begin{array}{c}\mathrm{C} \\
9.23 \pm 0.20 \\
\end{array}$ & $\begin{array}{c}\text { B } \\
8.77 \pm 0.16\end{array}$ & $\begin{array}{c}\mathrm{C} \\
8.00 \pm 0.14 \\
\end{array}$ & $\begin{array}{c}\mathrm{C} \\
8.50 \pm 0.19\end{array}$ & $\begin{array}{c}\text { B } \\
9.00 \pm 0.18\end{array}$ \\
\hline C. garepinus & $\begin{array}{c}\text { B } \\
8.55 \pm 0.15\end{array}$ & $\begin{array}{c}\mathrm{B} \\
9.55 \pm 0.15\end{array}$ & $\begin{array}{c}\mathrm{A} \\
9.60 \pm 0.16\end{array}$ & $\begin{array}{c}\mathrm{B} \\
8.55 \pm 0.15\end{array}$ & $\begin{array}{c}\mathrm{B} \\
8.90 \pm 0.19\end{array}$ & $\begin{array}{c}\mathrm{D} \\
8.50 \pm 0.15\end{array}$ \\
\hline C. carpio & $\begin{array}{c}\mathrm{A} \\
9.5 \pm 0.15\end{array}$ & $\begin{array}{c}\mathrm{A} \\
9.70 \pm 0.18\end{array}$ & $\begin{array}{c}\mathrm{A} \\
9.70 \pm 0.17\end{array}$ & $\begin{array}{c}\mathrm{A} \\
9.40 \pm 0.14\end{array}$ & $\begin{array}{c}\mathrm{A} \\
9.80 \pm 0.18\end{array}$ & $\begin{array}{c}\mathrm{A} \\
9.80 \pm 0.18\end{array}$ \\
\hline
\end{tabular}

Means within the same column of different litters are significantly different at $\mathrm{P}<0.01$ ).

Table (9): The PCV\% values in protozoan infected fish.

\begin{tabular}{|c|c|c|c|c|c|c|}
\hline Fish species & I. multifillus & Trichodina & Chilodenilla & Apizoma & Epistyles & $\begin{array}{c}\text { Mixed } \\
\text { infections }\end{array}$ \\
\hline O. niloticus & $\begin{array}{c}\text { B } \\
15.47 \pm 0.14\end{array}$ & $\begin{array}{c}\text { B } \\
16.50 \pm 0.15\end{array}$ & $\begin{array}{c}\text { B } \\
14.44 \pm 0.11\end{array}$ & $\begin{array}{c}\text { B } \\
15.49 \pm 0.19\end{array}$ & $\begin{array}{c}\text { B } \\
15.40 \pm 0.15\end{array}$ & $\begin{array}{c}\text { B } \\
13.49 \pm 0.13\end{array}$ \\
\hline M. cephalus & $\begin{array}{c}\mathrm{A} \\
16.50 \pm 0.15\end{array}$ & $\begin{array}{c}\mathrm{A} \\
16.55 \pm 0.12\end{array}$ & $\begin{array}{c}\mathrm{A} \\
15.43 \pm 0.12\end{array}$ & $\begin{array}{c}\text { B } \\
15.55 \pm 0.20\end{array}$ & $\begin{array}{c}\text { B } \\
15.44 \pm 0.16 \\
\end{array}$ & $\begin{array}{c}\text { B } \\
13.55 \pm 0.14\end{array}$ \\
\hline C. garepinus & $\begin{array}{c}\mathrm{A} \\
16.47 \pm 0.16\end{array}$ & $\begin{array}{c}\mathrm{C} \\
15.47 \pm 0.17\end{array}$ & $\begin{array}{c}\mathrm{A} \\
15.48 \pm 0.18\end{array}$ & $\begin{array}{c}\mathrm{A} \\
16.55 \pm 0.16\end{array}$ & $\begin{array}{c}\mathrm{A} \\
17.49 \pm 0.17\end{array}$ & $\begin{array}{c}\mathrm{A} \\
14.49 \pm 0.14\end{array}$ \\
\hline C. carpio & $\begin{array}{c}\mathrm{C} \\
10.44 \pm 0.14\end{array}$ & $\begin{array}{c}\mathrm{D} \\
11.45 \pm 0.14\end{array}$ & $\begin{array}{c}\mathrm{C} \\
12.47 \pm 0.17\end{array}$ & $\begin{array}{c}\mathrm{C} \\
12.45 \pm 0.12\end{array}$ & $\begin{array}{c}\mathrm{C} \\
13.47 \pm 0.14\end{array}$ & $\begin{array}{c}\mathrm{C} \\
9.45 \pm 0.09\end{array}$ \\
\hline
\end{tabular}

Means within the same column of different litters are significantly different at $\mathrm{P}<0.01$ ).

Table (10): The effect of parasitic infections on lymphocyte pecent in examined fish.

\begin{tabular}{|c|c|c|c|c|c|c|}
\hline Fish species & I. multifillus & Trichodina & Chilodenilla & Apizoma & Epistyles & $\begin{array}{c}\text { Mixed } \\
\text { infections }\end{array}$ \\
\hline O. niloticus & $\begin{array}{c}\mathrm{B} \\
48.5 \pm 4.15\end{array}$ & $\begin{array}{c}C \mathrm{C} \\
46.55 \pm 4.15 \\
\end{array}$ & $\begin{array}{c}\mathrm{C} \\
44.47 \pm 4.17 \\
\end{array}$ & $\begin{array}{c}\text { B } \\
46.44 \pm 4.16 \\
\end{array}$ & $\begin{array}{c}\text { B } \\
43.44 \pm 4.13 \\
\end{array}$ & $\begin{array}{c}\mathrm{B} \\
48.5 \pm 4.19 \\
\end{array}$ \\
\hline M. cephalus & $\begin{array}{c}\text { B } \\
48.7 \pm 4.17\end{array}$ & $\begin{array}{c}\text { B } \\
47.51 \pm 4.16\end{array}$ & $\begin{array}{c}\text { B } \\
46.77 \pm 4.18\end{array}$ & $\begin{array}{c}\mathrm{B} \\
46.49 \pm 4.19\end{array}$ & $\begin{array}{c}\text { B } \\
43.47 \pm 4.13\end{array}$ & $\begin{array}{c}\mathrm{B} \\
48.7 \pm 4.19\end{array}$ \\
\hline C. garepinus & $\begin{array}{c}\mathrm{A} \\
49.55 \pm 4.49\end{array}$ & $\begin{array}{c}\mathrm{A} \\
48.60 \pm 4.16\end{array}$ & $\begin{array}{c}\mathrm{A} \\
49.55 \pm 4.19\end{array}$ & $\begin{array}{c}\mathrm{A} \\
49.55 \pm 4.15\end{array}$ & $\begin{array}{c}\mathrm{A} \\
45.55 \pm 4.15\end{array}$ & $\begin{array}{c}\mathrm{A} \\
49.55 \pm 4.15\end{array}$ \\
\hline C. carpio & $\begin{array}{c}\mathrm{C} \\
42.33 \pm 4.13\end{array}$ & $\begin{array}{c}\mathrm{D} \\
40.35 \pm 4.13\end{array}$ & $\begin{array}{c}\mathrm{D} \\
39.33 \pm 4.14\end{array}$ & $\begin{array}{c}\mathrm{C} \\
40.22 \pm 4.12\end{array}$ & $\begin{array}{c}\mathrm{C} \\
38.33 \pm 3.19\end{array}$ & $\begin{array}{c}\mathrm{C} \\
43.33 \pm 4.13\end{array}$ \\
\hline
\end{tabular}

Means within the same column of different litters are significantly different at $\mathrm{P}<0.01$ ).

Kafrelsheikh Vet. Med. J. Vol. 13 No. 1 (2015) 
Prevalence Of Ectociliate Diseases In Cultured ...

Table (11): Eosinophilic percent in protozoal ciliates infected fish.

\begin{tabular}{|c|c|c|c|c|c|c|}
\hline Fish species & I. multifillus & Trichodina & Chilodenilla & Apizoma & Epistyles & $\begin{array}{c}\text { Mixed } \\
\text { infections }\end{array}$ \\
\hline O. niloticus & $\begin{array}{c}\mathrm{D} \\
14.43 \pm 3.14\end{array}$ & $\begin{array}{c}\mathrm{C} \\
13.33 \pm 3.19\end{array}$ & $\begin{array}{c}\mathrm{D} \\
14.44 \pm 4.16\end{array}$ & $\begin{array}{c}C \\
13.33 \pm 4.13\end{array}$ & $\begin{array}{c}\mathrm{D} \\
13.30 \pm 3.14\end{array}$ & $\begin{array}{c}\mathrm{D} \\
13.44 \pm 1.34\end{array}$ \\
\hline M. cephalus & $\begin{array}{c}\mathrm{C} \\
15.44 \pm 3.17\end{array}$ & $\begin{array}{c}\text { B } \\
15.34 \pm 3.18\end{array}$ & $\begin{array}{c}\mathrm{C} \\
14.90 \pm 4.18\end{array}$ & $\begin{array}{c}\mathrm{C} \\
13.38 \pm 4.15\end{array}$ & $\begin{array}{c}\mathrm{C} \\
14.80 \pm 3.17\end{array}$ & $\begin{array}{c}\mathrm{C} \\
14.45 \pm 1.36\end{array}$ \\
\hline C. garepinus & $\begin{array}{c}\mathrm{A} \\
17.54 \pm 4.15\end{array}$ & $\begin{array}{c}\mathrm{A} \\
17.54 \pm 4.17\end{array}$ & $\begin{array}{c}\mathrm{A} \\
17.52 \pm 4.12\end{array}$ & $\begin{array}{c}\mathrm{A} \\
16.44 \pm 4.11\end{array}$ & $\begin{array}{c}\mathrm{A} \\
18.55 \pm 2.16\end{array}$ & $\begin{array}{c}\mathrm{A} \\
16.44 \pm 4.17\end{array}$ \\
\hline C. carpio & $\begin{array}{c}\mathrm{B} \\
16.77 \pm 4.17\end{array}$ & $\begin{array}{c}\mathrm{B} \\
15.78 \pm 4.19\end{array}$ & $\begin{array}{c}\mathrm{B} \\
16.78 \pm 4.17\end{array}$ & $\begin{array}{c}\mathrm{B} \\
15.44 \pm 4.17\end{array}$ & $\begin{array}{c}\mathrm{B} \\
15.78 \pm 2.17\end{array}$ & $\begin{array}{c}\mathrm{B} \\
15.33 \pm 3.15\end{array}$ \\
\hline
\end{tabular}

Means within the same column of different litters are significantly different at $\mathrm{P}<0.01$ ).

Table (12): Basophilic percent in protozoals infected fish.

\begin{tabular}{|c|c|c|c|c|c|c|}
\hline Fish species & I. multifillus & Trichodina & Chilodenilla & Apizoma & Epistyles & $\begin{array}{c}\text { Mixed } \\
\text { infections }\end{array}$ \\
\hline O. niloticus & $\begin{array}{c}\mathrm{C} \\
11.88 \pm 1.19 \\
\end{array}$ & $\begin{array}{c}\mathrm{C} \\
10.89 \pm 1.19\end{array}$ & $\begin{array}{c}\mathrm{B} \\
11.83 \pm 1.14\end{array}$ & $\begin{array}{c}\mathrm{C} \\
10.88 \pm 0.18 \\
\end{array}$ & $\begin{array}{c}\mathrm{B} \\
10.88 \pm 0.88\end{array}$ & $\begin{array}{c}\mathrm{C} \\
10.88 \pm 1.18 \\
\end{array}$ \\
\hline M. cephalus & $\begin{array}{c}\text { B } \\
12.77 \pm 1.18\end{array}$ & $\begin{array}{c}\text { B } \\
11.90 \pm 1.18\end{array}$ & $\begin{array}{c}\mathrm{A} \\
12.84 \pm 1.17\end{array}$ & $\begin{array}{c}\mathrm{B} \\
11.80 \pm 0.12\end{array}$ & $\begin{array}{c}\mathrm{B} \\
10.90 \pm 0.81\end{array}$ & $\begin{array}{c}\text { B } \\
11.90 \pm 1.17\end{array}$ \\
\hline C. garepinus & $\begin{array}{c}\mathrm{A} \\
13.64 \pm 1.16\end{array}$ & $\begin{array}{c}\mathrm{A} \\
12.33 \pm 1.12\end{array}$ & $\begin{array}{c}\mathrm{A} \\
12.44 \pm 1.12\end{array}$ & $\begin{array}{c}\mathrm{A} \\
12.64 \pm 1.11\end{array}$ & $\begin{array}{c}\mathrm{A} \\
11.64 \pm 0.66\end{array}$ & $\begin{array}{c}\mathrm{A} \\
12.64 \pm 1.14\end{array}$ \\
\hline C. carpio & $\begin{array}{c}\mathrm{D} \\
8.89 \pm 1.18\end{array}$ & $\begin{array}{c}\mathrm{D} \\
7.88 \pm 1.18\end{array}$ & $\begin{array}{c}\mathrm{C} \\
8.88 \pm 0.77\end{array}$ & $\begin{array}{c}\mathrm{D} \\
8.89 \pm 0.99\end{array}$ & $\begin{array}{c}\mathrm{C} \\
7.89 \pm 0.77\end{array}$ & $\begin{array}{c}\mathrm{D} \\
7.88 \pm 0.78\end{array}$ \\
\hline
\end{tabular}

Means within the same column of different litters are significantly different at $\mathrm{P}<0.01$ ).

Table (13): Monocytic percent in protozoal ciliates infected fish.

\begin{tabular}{|c|c|c|c|c|c|c|}
\hline Fish species & I. multifillus & Trichodina & Chilodenilla & Apizoma & Epistyles & $\begin{array}{c}\text { Mixed } \\
\text { infections }\end{array}$ \\
\hline O. niloticus & $\begin{array}{c}\text { B } \\
8.44 \pm 0.14\end{array}$ & $\begin{array}{c}\mathrm{C} \\
7.33 \pm 0.17\end{array}$ & $\begin{array}{c}\text { B } \\
6.34 \pm 0.16\end{array}$ & $\begin{array}{c}\text { B } \\
7.30 \pm 0.17\end{array}$ & $\begin{array}{c}\text { B } \\
7.32 \pm 0.17\end{array}$ & $\begin{array}{c}\mathrm{C} \\
8.31 \pm 0.18\end{array}$ \\
\hline M. cephalus & $\begin{array}{c}\mathrm{B} \\
8.70 \pm 0.16\end{array}$ & $\begin{array}{c}\mathrm{B} \\
7.50 \pm 0.19\end{array}$ & $\begin{array}{c}\mathrm{A} \\
7.40 \pm 0.19\end{array}$ & $\begin{array}{c}\text { B } \\
7.35 \pm 0.18\end{array}$ & $\begin{array}{c}\text { B } \\
7.35 \pm 0.19\end{array}$ & $\begin{array}{c}\text { B } \\
8.45 \pm 0.19\end{array}$ \\
\hline C. garepinus & $\begin{array}{c}\mathrm{A} \\
9.40 \pm 0.19\end{array}$ & $\begin{array}{c}\mathrm{A} \\
8.44 \pm 0.18\end{array}$ & $\begin{array}{c}\mathrm{A} \\
7.43 \pm 0.17\end{array}$ & $\begin{array}{c}\mathrm{A} \\
8.41 \pm 0.18\end{array}$ & $\begin{array}{c}\mathrm{A} \\
8.42 \pm 0.18\end{array}$ & $\begin{array}{c}\mathrm{A} \\
9.42 \pm 0.19\end{array}$ \\
\hline C. carpio & $\begin{array}{c}\mathrm{C} \\
7.30 .44 \pm 0.17\end{array}$ & $\begin{array}{c}\text { B } \\
7.44 \pm 0.17\end{array}$ & $\begin{array}{c}\mathrm{B} \\
6.43 \pm 0.16\end{array}$ & $\begin{array}{c}\text { B } \\
7.41 \pm 0.16\end{array}$ & $\begin{array}{c}\text { B } \\
7.41 \pm 0.14\end{array}$ & $\begin{array}{c}\text { B } \\
8.43 \pm 0.14\end{array}$ \\
\hline
\end{tabular}

Means within the same column of different litters are significantly different at $\mathrm{P}<0.01$ ).

$\overline{\text { Kafrelsheikh Vet. Med. J. Vol. } 13 \text { No. } 1 \text { (2015) }}$ 
Table (14): Neutrophilic percent in protozoal ciliates infected fish.

\begin{tabular}{|c|c|c|c|c|c|c|}
\hline Fish species & I. multifillus & Trichodina & Chilodenilla & Apizoma & Epistyles & $\begin{array}{c}\text { Mixed } \\
\text { infections }\end{array}$ \\
\hline O. niloticus & $\begin{array}{c}\mathrm{C} \\
24.55 \pm 2.24\end{array}$ & $\begin{array}{c}\mathrm{C} \\
23.44 \pm 2.24\end{array}$ & $\begin{array}{c}\mathrm{C} \\
24.56 \pm 1.17\end{array}$ & $\begin{array}{c}\mathrm{C} \\
25.54 \pm 2.26\end{array}$ & $\begin{array}{c}\mathrm{C} \\
25.45 \pm 2.24\end{array}$ & $\begin{array}{c}\mathrm{C} \\
26.58 \pm 2.29\end{array}$ \\
\hline M. cephalus & $\begin{array}{c}\mathrm{B} \\
25.55 \pm 2.25\end{array}$ & $\begin{array}{c}\text { B } \\
24.46 \pm 2.14\end{array}$ & $\begin{array}{c}\mathrm{B} \\
26.56 \pm 1.14\end{array}$ & $\begin{array}{c}\text { B } \\
26.55 \pm 2.27\end{array}$ & $\begin{array}{c}\text { B } \\
26.44 \pm 2.24\end{array}$ & $\begin{array}{c}\mathrm{B} \\
27.55 \pm 2.22\end{array}$ \\
\hline C. garepinus & $\begin{array}{c}\mathrm{A} \\
26.27 \pm 2.28\end{array}$ & $\begin{array}{c}\mathrm{A} \\
26.28 \pm 2.26\end{array}$ & $\begin{array}{c}\mathrm{A} \\
27.20 \pm 2.18\end{array}$ & $\begin{array}{c}\mathrm{A} \\
27.28 \pm 2.29\end{array}$ & $\begin{array}{c}\mathrm{A} \\
27.28 \pm 2.29\end{array}$ & $\begin{array}{c}\mathrm{A} \\
28.29 \pm 2.28\end{array}$ \\
\hline C. carpio & $\begin{array}{c}\mathrm{D} \\
21.5 \pm 2.21\end{array}$ & $\begin{array}{c}\mathrm{D} \\
21.55 \pm 2.24\end{array}$ & $\begin{array}{c}\mathrm{D} \\
22.15 \pm 2.22\end{array}$ & $\begin{array}{c}\mathrm{D} \\
23.50 \pm 2.23\end{array}$ & $\begin{array}{c}\mathrm{D} \\
22.5 \pm 2.25\end{array}$ & $\begin{array}{c}\mathrm{D} \\
22.53 \pm 2.53\end{array}$ \\
\hline
\end{tabular}

Means within the same column of different litters are significantly different at $\mathrm{P}<0.01$ ).

Table (15): The total serum protein levels in protozoal infected fish $(\mathrm{g} / \mathrm{dL})$.

\begin{tabular}{|c|c|c|c|c|c|c|}
\hline Fish species & I. multifillus & Trichodina & Chilodenilla & Apizoma & Epistyles & $\begin{array}{c}\text { Mixed } \\
\text { infections }\end{array}$ \\
\hline O. niloticus & $\begin{array}{c}\mathrm{C} \\
3.88 \pm 0.85\end{array}$ & $\begin{array}{c}\mathrm{A} \\
4.87 \pm 0.40\end{array}$ & $\begin{array}{c}\text { B } \\
4.88 \pm 0.33\end{array}$ & $\begin{array}{c}\mathrm{C} \\
3.75 \pm 0.35\end{array}$ & $\begin{array}{c}\mathrm{B} \\
3.55 \pm 0.35\end{array}$ & $\begin{array}{c}\text { B } \\
4.88 \pm 0.44\end{array}$ \\
\hline M. cephalus & $\begin{array}{c}\mathrm{A} \\
4.88 \pm 0.55\end{array}$ & $\begin{array}{c}\mathrm{A} \\
4.89 \pm 0.40\end{array}$ & $\begin{array}{c}\mathrm{A} \\
5.88 \pm 0.33\end{array}$ & $\begin{array}{c}\mathrm{A} \\
4.75 \pm 0.35\end{array}$ & $\begin{array}{c}\mathrm{C} \\
3.53 \pm 0.35\end{array}$ & $\begin{array}{c}\mathrm{C} \\
4.22 \pm 0.44\end{array}$ \\
\hline C. garepinus & $\begin{array}{c}\text { B } \\
4 \pm 0.42 \\
\end{array}$ & $\begin{array}{c}\text { B } \\
4.12 \pm 0.42\end{array}$ & $\begin{array}{c}\text { B } \\
4.55 \pm 0.45\end{array}$ & $\begin{array}{c}\text { B } \\
4.22 \pm 0.22\end{array}$ & $\begin{array}{c}\text { A } \\
4.77 \pm 0.47\end{array}$ & $\begin{array}{c}\mathrm{A} \\
5.52 \pm 0.51\end{array}$ \\
\hline C. carpio & $\begin{array}{c}\text { B } \\
4.09 \pm 0.41\end{array}$ & $\begin{array}{c}\mathrm{AB} \\
4.55 \pm 0.41\end{array}$ & $\begin{array}{c}\mathrm{A} \\
5.66 \pm 0.51\end{array}$ & $\begin{array}{c}\mathrm{A} \\
4.66 \pm 0.46\end{array}$ & $\begin{array}{c}\mathrm{A} \\
4.99 \pm 0.45\end{array}$ & $\begin{array}{c}\mathrm{A} \\
5.66 \pm 0.44\end{array}$ \\
\hline
\end{tabular}

Means within the same column of different litters are significantly different at $\mathrm{P}<0.01$ ).

Table (16): The serum albumin levels in protozoal infected fish (g/dL).

\begin{tabular}{|c|c|c|c|c|c|c|}
\hline Fish species & $\begin{array}{c}\text { I. } \\
\text { multifillus }\end{array}$ & Trichodina & Chilodenilla & Apizoma & Epistyles & $\begin{array}{c}\text { Mixed } \\
\text { infections }\end{array}$ \\
\hline O. niloticus & $\begin{array}{c}\mathrm{C} \\
0.62 \pm 0.12 \\
\end{array}$ & $\begin{array}{c}\mathrm{C} \\
0.60 \pm 0.16\end{array}$ & $\begin{array}{c}C \\
0.61 \pm 0.44\end{array}$ & $\begin{array}{c}C \\
0.60 \pm 0.42\end{array}$ & $\begin{array}{c}\mathrm{D} \\
0.61 \pm 0.45\end{array}$ & $\begin{array}{c}C \\
0.64 \pm 0.16\end{array}$ \\
\hline M. cephalus & $\begin{array}{c}\mathrm{C} \\
0.63 \pm 0.11\end{array}$ & $\begin{array}{c}\mathrm{BC} \\
0.61 \pm 0.16\end{array}$ & $\begin{array}{c}\text { B } \\
0.67 \pm 0.44\end{array}$ & $\begin{array}{c}\text { B } \\
0.64 \pm 0.42\end{array}$ & $\begin{array}{c}\mathrm{Cb} \\
0.65 \pm 0.44\end{array}$ & $\begin{array}{c}C \\
0.65 \pm 0.18\end{array}$ \\
\hline C. garepinus & $\begin{array}{c}\mathrm{B} \\
0.66 \pm 0.16\end{array}$ & $\begin{array}{c}\mathrm{BC} \\
0.62 \pm 0.55\end{array}$ & $\begin{array}{c}C \\
0.63 \pm 0.55\end{array}$ & $\begin{array}{c}\text { B } \\
0.63 \pm 0.43\end{array}$ & $\begin{array}{c}\mathrm{A} \\
0.74 \pm 0.42\end{array}$ & $\begin{array}{c}\mathrm{A} \\
0.77 \pm 0.14\end{array}$ \\
\hline C. carpio & $\begin{array}{c}\mathrm{A} \\
0.76 \pm 0.17\end{array}$ & $\begin{array}{c}\text { A } \\
0.73 \pm 0.45\end{array}$ & $\begin{array}{c}\mathrm{A} \\
0.72 \pm 0.45\end{array}$ & $\begin{array}{c}\mathrm{A} \\
0.73 \pm 0.45\end{array}$ & $\begin{array}{c}\text { B } \\
0.70 \pm 0.45\end{array}$ & $\begin{array}{c}\text { B } \\
0.70 \pm 0.17\end{array}$ \\
\hline
\end{tabular}

Means within the same column of different litters are significantly different at $\mathrm{P}<0.01$ ).

$\overline{\text { Kafrelsheikh Vet. Med. J. Vol. } 13 \text { No. } 1 \text { (2015) }}$ 
Prevalence Of Ectociliate Diseases In Cultured ...

Table (17): The serum globulin levels in protozoal ciliates infected fish (g/dL).

\begin{tabular}{|c|c|c|c|c|c|c|}
\hline Fish species & I. multifillus & Trichodina & Chilodenilla & Apizoma & Epistyles & $\begin{array}{c}\text { Mixed } \\
\text { infections }\end{array}$ \\
\hline O. niloticus & $\begin{array}{c}\mathrm{B} \\
3.26 \pm 0.27\end{array}$ & $\begin{array}{c}\mathrm{A} \\
4.27 \pm 0.29\end{array}$ & $\begin{array}{c}\mathrm{C} \\
4.27 \pm 0.39\end{array}$ & $\begin{array}{c}\mathrm{D} \\
3.15 \pm 0.33\end{array}$ & $\begin{array}{c}\mathrm{B} \\
2.94 \pm 0.44\end{array}$ & $\begin{array}{c}\mathrm{C} \\
4.24 \pm 0.44\end{array}$ \\
\hline M. cephalus & $\begin{array}{c}\mathrm{A} \\
4.25 \pm 0.25\end{array}$ & $\begin{array}{c}\mathrm{A} \\
4.18 \pm 0.28\end{array}$ & $\begin{array}{c}\mathrm{A} \\
5.21 \pm 0.55\end{array}$ & $\begin{array}{c}\mathrm{A} \\
4.11 \pm 0.45\end{array}$ & $\begin{array}{c}\mathrm{B} \\
2.88 \pm 0.29\end{array}$ & $\begin{array}{c}\mathrm{D} \\
3.57 \pm 0.55\end{array}$ \\
\hline C. garepinus & $\begin{array}{c}\mathrm{B} \\
3.34 \pm 0.28\end{array}$ & $\begin{array}{c}\mathrm{B} \\
3.50 \pm 0.29\end{array}$ & $\begin{array}{c}\mathrm{D} \\
3.92 \pm 0.44\end{array}$ & $\begin{array}{c}\mathrm{C} \\
3.59 \pm 0.39\end{array}$ & $\begin{array}{c}\mathrm{A} \\
4.03 \pm 0.44\end{array}$ & $\begin{array}{c}\mathrm{B} \\
4.75 \pm 0.44\end{array}$ \\
\hline C. carpio & $\begin{array}{c}\mathrm{B} \\
3.33 \pm 0.35\end{array}$ & $\begin{array}{c}\mathrm{B} \\
3.82 \pm 0.55\end{array}$ & $\begin{array}{c}\mathrm{B} \\
4.94 \pm 0.44\end{array}$ & $\begin{array}{c}\mathrm{B} \\
3.93 \pm 0.44\end{array}$ & $\begin{array}{c}\mathrm{A} \\
4.29 \pm 0.44\end{array}$ & $\begin{array}{c}\mathrm{A} \\
4.96 \pm 0.66\end{array}$ \\
\hline
\end{tabular}

Means within the same column of different litters are significantly different at $\mathrm{P}<0.01$ ).

Table (18): The albumin/globulins ratio in protozoal ciliates infected fish.

\begin{tabular}{|c|c|c|c|c|c|c|}
\hline $\begin{array}{c}\text { Fish } \\
\text { species }\end{array}$ & I. multifillus & Trichodina & Chilodenilla & Apizoma & Epistyles & $\begin{array}{c}\text { Mixed } \\
\text { infections }\end{array}$ \\
\hline O. niloticus & $\begin{array}{c}\mathrm{B} \\
5.25 \pm 0.26\end{array}$ & $\begin{array}{c}\mathrm{A} \\
7.11 \pm 0.55\end{array}$ & $\begin{array}{c}\text { B } \\
7 \pm 0.82\end{array}$ & $\begin{array}{c}C \\
5.25 \pm 0.55\end{array}$ & $\begin{array}{c}\mathrm{C} \\
4.81 \pm 0.84\end{array}$ & $\begin{array}{c}\mathrm{D} \\
3.50 \pm 0.55\end{array}$ \\
\hline $\begin{array}{c}\text { M. } \\
\text { cephalus }\end{array}$ & $\begin{array}{c}\text { A } \\
6.74 \pm 0.28 \\
\end{array}$ & $\begin{array}{c}\mathrm{B} \\
6.85 \pm 0.66\end{array}$ & $\begin{array}{c}\mathrm{A} \\
7.78 \pm 0.77\end{array}$ & $\begin{array}{c}\mathrm{A} \\
6.43 \pm 0.66\end{array}$ & $\begin{array}{c}\mathrm{D} \\
4.43 \pm 0.44\end{array}$ & $\begin{array}{c}\mathrm{C} \\
5.49 \pm 0.49\end{array}$ \\
\hline $\begin{array}{c}C . \\
\text { garepinus }\end{array}$ & $\begin{array}{c}\mathrm{B} \\
5.06 \pm 0.35\end{array}$ & $\begin{array}{c}\mathrm{C} \\
5.64 \pm 0.64\end{array}$ & $\begin{array}{c}\mathrm{D} \\
6.23 \pm 0.69\end{array}$ & $\begin{array}{c}\mathrm{B} \\
5.69 \pm 0.66\end{array}$ & $\begin{array}{c}\text { B } \\
5.44 \pm 0.44\end{array}$ & $\begin{array}{c}\mathrm{B} \\
6.17 \pm 0.61\end{array}$ \\
\hline C. carpio & $\begin{array}{c}\mathrm{C} \\
4.38 \pm 0.43\end{array}$ & $\begin{array}{c}C \\
5.23 \pm 0.55\end{array}$ & $\begin{array}{c}C \\
6.86 \pm 0.86\end{array}$ & $\begin{array}{c}\mathrm{C} \\
5.38 \pm 0.88\end{array}$ & $\begin{array}{c}\mathrm{A} \\
6.12 \pm 0.62\end{array}$ & $\begin{array}{c}\mathrm{A} \\
7.08 \pm 0.70\end{array}$ \\
\hline
\end{tabular}

Means within the same column of different litters are significantly different at $\mathrm{P}<0.01$ ).

Table (19): The S.ALT levels (U/I) in protozoal ciliates infected fish .

\begin{tabular}{|c|c|c|c|c|c|c|}
\hline Fish species & I. multifillus & Trichodina & Chilodenilla & Apizoma & Epistyles & $\begin{array}{c}\text { Mixed } \\
\text { infections }\end{array}$ \\
\hline O. niloticus & $\begin{array}{c}\mathrm{D} \\
76.45 \pm 6.44\end{array}$ & $\begin{array}{c}\mathrm{D} \\
73.44 \pm 4.70\end{array}$ & $\begin{array}{c}\mathrm{D} \\
76.45 \pm 4.75\end{array}$ & $\begin{array}{c}\mathrm{D} \\
77.45 \pm 4.77\end{array}$ & $\begin{array}{c}\mathrm{D} \\
75.45 \pm 4.75\end{array}$ & $\begin{array}{c}\mathrm{D} \\
77.40 \pm 4.71\end{array}$ \\
\hline M. cephalus & $\begin{array}{c}\mathrm{C} \\
78.45 \pm 6.45\end{array}$ & $\begin{array}{c}\mathrm{C} \\
75.44 \pm 4.72\end{array}$ & $\begin{array}{c}\mathrm{C} \\
78.45 \pm 4.76\end{array}$ & $\begin{array}{c}\mathrm{C} \\
79.45 \pm 4.79\end{array}$ & $\begin{array}{c}\mathrm{C} \\
80.43 \pm 4.80\end{array}$ & $\begin{array}{c}\mathrm{C} \\
82.40 \pm 4.90\end{array}$ \\
\hline C. garepinus & $\begin{array}{c}\mathrm{A} \\
85.77 \pm 5.71\end{array}$ & $\begin{array}{c}\text { B } \\
81.77 \pm 4.72\end{array}$ & $\begin{array}{c}\text { A } \\
86.77 \pm 6.77\end{array}$ & $\begin{array}{c}\mathrm{A} \\
85.77 \pm 5.77\end{array}$ & $\begin{array}{c}\mathrm{A} \\
84.77 \pm 4.80\end{array}$ & $\begin{array}{c}\mathrm{A} \\
87.77 \pm 4.77\end{array}$ \\
\hline C. carpio & $\begin{array}{c}\text { B } \\
82.44 \pm 4.44\end{array}$ & $\begin{array}{c}\mathrm{A} \\
82.43 \pm 4.45\end{array}$ & $\begin{array}{c}\text { B } \\
83.44 \pm 4.88\end{array}$ & $\begin{array}{c}\text { B } \\
83.43 \pm 488\end{array}$ & $\begin{array}{c}\mathrm{A} \\
83.44 \pm 4.88\end{array}$ & $\begin{array}{c}\text { B } \\
83.40 \pm 3.88\end{array}$ \\
\hline
\end{tabular}

Means within the same column of different litters are significantly different at $\mathrm{P}<0.01$ ).

$\overline{\text { Kafrelsheikh Vet. Med. J. Vol. } 13 \text { No. } 1 \text { (2015) }}$ 
Table (20): The S.AST levels (U/I) in protozoans infected fish.

\begin{tabular}{|c|c|c|c|c|c|c|}
\hline Fish species & I. multifillus & Trichodina & Chilodenilla & Apizoma & Epistyles & $\begin{array}{c}\text { Mixed } \\
\text { infections }\end{array}$ \\
\hline O. niloticus & $\begin{array}{c}\mathrm{C} \\
24.88 \pm 4.87 \\
\end{array}$ & $\begin{array}{c}\mathrm{C} \\
25.88 \pm 5.44\end{array}$ & $\begin{array}{c}\mathrm{C} \\
25.88 \pm 2.37\end{array}$ & $\begin{array}{c}\mathrm{C} \\
23.88 \pm 3.84\end{array}$ & $\begin{array}{c}\mathrm{C} \\
23.87 \pm 3.88 \\
\end{array}$ & $\begin{array}{c}\mathrm{C} \\
25.88 \pm 2.87\end{array}$ \\
\hline M. cephalus & $\begin{array}{c}\text { B } \\
26.89 \pm 4.88\end{array}$ & $\begin{array}{c}\text { B } \\
27.89 \pm 5.45\end{array}$ & $\begin{array}{c}\mathrm{B} \\
27.88 \pm 2.38\end{array}$ & $\begin{array}{c}\text { B } \\
25.88 \pm 3.85\end{array}$ & $\begin{array}{c}\text { B } \\
25.88 \pm 3.88\end{array}$ & $\begin{array}{c}\text { B } \\
27.89 \pm 2.88\end{array}$ \\
\hline C. garepinus & $\begin{array}{c}\mathrm{A} \\
30.24 \pm 3.22 \\
\end{array}$ & $\begin{array}{c}\mathrm{A} \\
31.24 \pm 3.44 \\
\end{array}$ & $\begin{array}{c}\mathrm{A} \\
30.22 \pm 2.34\end{array}$ & $\begin{array}{c}\mathrm{A} \\
31.24 \pm 2.31 \\
\end{array}$ & $\begin{array}{c}\mathrm{A} \\
30.22 \pm 3.22 \\
\end{array}$ & $\begin{array}{c}\mathrm{A} \\
32.24 \pm 3.22 \\
\end{array}$ \\
\hline C. carpio & $\begin{array}{c}\mathrm{D} \\
18.22 \pm 3.82\end{array}$ & $\begin{array}{c}\mathrm{D} \\
19.22 \pm 1.20\end{array}$ & $\begin{array}{c}\mathrm{D} \\
18.25 \pm 2.44\end{array}$ & $\begin{array}{c}\mathrm{D} \\
18.21 \pm 2.35\end{array}$ & $\begin{array}{c}\mathrm{D} \\
19.22 \pm 2.19\end{array}$ & $\begin{array}{c}\text { D } \\
20.22 \pm 2.24\end{array}$ \\
\hline
\end{tabular}

Means within the same column of different litters are significantly different at $\mathrm{P}<0.01$ ).

Table (21): The S.ALP levels (U/I) in protozoal ciliates infected fish.

\begin{tabular}{|c|c|c|c|c|c|c|}
\hline Fish species & $\begin{array}{c}\text { I. } \\
\text { multifillus }\end{array}$ & Trichodina & Chilodenilla & Apizoma & Epistyles & $\begin{array}{c}\text { Mixed } \\
\text { infections }\end{array}$ \\
\hline O. niloticus & $\begin{array}{c}\mathrm{C} \\
14.77 \pm 1.71 \\
\end{array}$ & $\begin{array}{c}\mathrm{C} \\
14.55 \pm 1.14 \\
\end{array}$ & $\begin{array}{c}\mathrm{C} \\
13.22 \pm 1.14\end{array}$ & $\begin{array}{c}\text { B } \\
13.44 \pm 1.15 \\
\end{array}$ & $\begin{array}{c}\mathrm{AB} \\
15.44 \pm 1.16 \\
\end{array}$ & $\begin{array}{c}\mathrm{B} \\
12.43 \pm 1.12 \\
\end{array}$ \\
\hline M. cephalus & $\begin{array}{c}\text { B } \\
15.76 \pm 1.72 \\
\end{array}$ & $\begin{array}{c}\mathrm{B} \\
15.57 \pm 1.15 \\
\end{array}$ & $\begin{array}{c}\text { B } \\
14.22 \pm 1.15\end{array}$ & $\begin{array}{c}\mathrm{AB} \\
14.45 \pm 1.16 \\
\end{array}$ & $\begin{array}{c}\mathrm{AB} \\
15.49 \pm 1.18 \\
\end{array}$ & $\begin{array}{c}\mathrm{AB} \\
12.19 \pm 1.19 \\
\end{array}$ \\
\hline C. garepinus & $\begin{array}{c}\mathrm{A} \\
16.77 \pm 1.16 \\
\end{array}$ & $\begin{array}{c}\mathrm{A} \\
16.55 \pm 1.15 \\
\end{array}$ & $\begin{array}{c}\mathrm{A} \\
15.55 \pm 1.16\end{array}$ & $\begin{array}{c}\mathrm{AB} \\
14.66 \pm 1.16 \\
\end{array}$ & $\begin{array}{c}\mathrm{A} \\
16.66 \pm 1.17 \\
\end{array}$ & $\begin{array}{c}\mathrm{A} \\
13.63 \pm 1.13 \\
\end{array}$ \\
\hline C. carpio & $\begin{array}{c}\mathrm{D} \\
13.36 \pm 1.14\end{array}$ & $\begin{array}{c}\mathrm{D} \\
13.34 \pm 1.14\end{array}$ & $\begin{array}{c}\mathrm{D} \\
12.33 \pm 1.14\end{array}$ & $\begin{array}{c}\text { B } \\
12.44 \pm 1.12\end{array}$ & $\begin{array}{c}\text { B } \\
14.44 \pm 1.14\end{array}$ & $\begin{array}{c}\mathrm{AB} \\
13.45 \pm 1.13\end{array}$ \\
\hline
\end{tabular}

Means within the same column of different litters are significantly different at $\mathrm{P}<0.01$ ).

Table (22): The phagocytic activity (PA) of protozoal ciliates infected fish.

\begin{tabular}{|c|c|c|c|c|c|c|}
\hline Fish species & I. multifillus & Trichodina & Chilodenilla & Apizoma & Epistyles & $\begin{array}{c}\text { Mixed } \\
\text { infections }\end{array}$ \\
\hline O. niloticus & $\begin{array}{c}\mathrm{C} \\
34.33 \pm 3.33\end{array}$ & $\begin{array}{c}\mathrm{C} \\
40.55 \pm 4.25\end{array}$ & $\begin{array}{c}\mathrm{D} \\
36.22 \pm 4.12\end{array}$ & $\begin{array}{c}\mathrm{D} \\
22.25 \pm 3.22\end{array}$ & $\begin{array}{c}\mathrm{D} \\
44.55 \pm 4.25\end{array}$ & $\begin{array}{c}C \mathrm{C} \\
55.66 \pm 5.66\end{array}$ \\
\hline M. cephalus & $\begin{array}{c}\mathrm{C} \\
34.36 \pm 3.32\end{array}$ & $\begin{array}{c}\text { B } \\
42.56 \pm 4.55\end{array}$ & $\begin{array}{c}\mathrm{C} \\
40.22 \pm 5.12\end{array}$ & $\begin{array}{c}C \\
28.25 \pm 4.23\end{array}$ & $\begin{array}{c}\mathrm{C} \\
45.56 \pm 4.22\end{array}$ & $\begin{array}{c}\text { B } \\
56.65 \pm 4.65\end{array}$ \\
\hline C. garepinus & $\begin{array}{c}\mathrm{A} \\
37.33 \pm 3.34\end{array}$ & $\begin{array}{c}\mathrm{A} \\
44.45 \pm 4.56\end{array}$ & $\begin{array}{c}\mathrm{A} \\
55.44 \pm 5.15\end{array}$ & $\begin{array}{c}\mathrm{A} \\
33.24 \pm 3.24\end{array}$ & $\begin{array}{c}\mathrm{A} \\
50.22 \pm 5.22\end{array}$ & $\begin{array}{c}\mathrm{A} \\
57.88 \pm 5.78\end{array}$ \\
\hline C. carpio & $\begin{array}{c}\text { B } \\
35.22 \pm 3.35\end{array}$ & $\begin{array}{c}\text { B } \\
41.22 \pm 4.12\end{array}$ & $\begin{array}{c}\text { B } \\
52.43 \pm 5.17\end{array}$ & $\begin{array}{c}\text { B } \\
30.22 \pm 3.25\end{array}$ & $\begin{array}{c}\text { B } \\
46.77 \pm 4.22\end{array}$ & $\begin{array}{c}\text { B } \\
56.55 \pm 5.56\end{array}$ \\
\hline
\end{tabular}

Means within the same column of different litters are significantly different at $\mathrm{P}<0.01$ ).

$\overline{\text { Kafrelsheikh Vet. Med. J. Vol. } 13 \text { No. } 1 \text { (2015) }}$ 
Prevalence Of Ectociliate Diseases In Cultured ...

Table (23): The phagocytic index (PI) of protozoal ciliates infected fish.

\begin{tabular}{|c|c|c|c|c|c|c|}
\hline Fish species & $\begin{array}{c}\text { I. } \\
\text { multifillus }\end{array}$ & Trichodina & Chilodenilla & Apizoma & Epistyles & $\begin{array}{c}\text { Mixed } \\
\text { infections }\end{array}$ \\
\hline O. niloticus & $\begin{array}{c}\text { B } \\
4.24 \pm 0.14\end{array}$ & $\begin{array}{c}\mathrm{A} \\
6.79 \pm 0.16\end{array}$ & $\begin{array}{c}\mathrm{C} \\
4.32 \pm 0.13\end{array}$ & $\begin{array}{c}\mathrm{D} \\
3.45 \pm 0.16\end{array}$ & $\begin{array}{c}\mathrm{A} \\
6.33 \pm 0.16\end{array}$ & $\begin{array}{c}\mathrm{A} \\
4.43 \pm 0.14\end{array}$ \\
\hline M. cephalus & $\begin{array}{c}\text { B } \\
4.27 \pm 0.14\end{array}$ & $\begin{array}{c}\text { A } \\
6.70 \pm 0.18\end{array}$ & $\begin{array}{c}\mathrm{C} \\
4.34 \pm 0.14\end{array}$ & $\begin{array}{c}\mathrm{C} \\
3.70 \pm 0.18\end{array}$ & $\begin{array}{c}\mathrm{A} \\
6.43 \pm 0.17\end{array}$ & $\begin{array}{c}\mathrm{A} \\
4.44 \pm 0.14\end{array}$ \\
\hline C. garepinus & $\begin{array}{c}\mathrm{A} \\
4.35 \pm 0.13\end{array}$ & $\begin{array}{c}\mathrm{A} \\
6.80 \pm 0.18\end{array}$ & $\begin{array}{c}\text { B } \\
5.44 \pm 0.15\end{array}$ & $\begin{array}{c}\mathrm{B} \\
4.20 \pm 0.15\end{array}$ & $\begin{array}{c}\text { B } \\
5.22 \pm 0.15\end{array}$ & $\begin{array}{c}\mathrm{A} \\
4.45 \pm 0.15\end{array}$ \\
\hline C. carpio & $\begin{array}{c}\mathrm{A} \\
4.37 \pm 0.17\end{array}$ & $\begin{array}{c}\text { B } \\
6.44 \pm 0.14\end{array}$ & $\begin{array}{c}\mathrm{A} \\
5.43 \pm 0.12\end{array}$ & $\begin{array}{c}\mathrm{A} \\
4.22 \pm 0.13\end{array}$ & $\begin{array}{c}\mathrm{A} \\
6.70 \pm 0.17\end{array}$ & $\begin{array}{c}\mathrm{A} \\
4.50 \pm 0.14\end{array}$ \\
\hline
\end{tabular}

Means within the same column of different litters are significantly different at $\mathrm{P}<0.01$ ).

\section{REFERENCES}

- Abboud, O.A.S.(2001). The effect of chilodonellosis on platy fish and its treatment.The Second International Scientific Conference. Mansoura Univeristy,8-9 April,pp.583-587.

- Abd El-Aal, A.M.I. (2002). Studies on tissue parasites in fiosh. Ph. D. Thesis Fac. Vet. Med. Tanta Univ. (Kafr El-Sheikh Branch).

- Abd El-Gawad, R.A. (2004). Studies on ectoparasites of Freshwater fish. M.V.Sc. Thesis, Zagazig University.

- Abd El-Khalek, H. M. (1998). Studies on the ectoparasites of some freswater fishes in Benisuef Governorate. M.V.Sc. Thesis. Fac. Vet. Med. Beni-Suef Univ.

- Abd El-Megiuid, M. (1989). Parasitological and histological studies on the Grass carp raised in the Delta breading station in Egypt. M.V.Sc. Thesis Fac. Science, Ain Shames Univ., Egypt.

- Abu El-Kheir, S. A. (2006). Studies on the external protozoal parasites in catfish (Clarias garepinus) in Dakahlia Province. Kafr ElSheikh Vet. Med. J. 44 (1). 859 - 879. 
- Alvarez-Pellitero, P. (2008). Fish immunity and parasite infections: from innate immunity to immunoprophylactic prospects. Vet. Immunol. Immunopathol.,; 126: 171-198.

- Awad, M. H. M. A. (2007). An approach to the internal parasitic infections in diseased freshwater fishes. M.V.Sc. Thesis, Fac. Vet. Med. Cairo Univ.

- Awad.M.H.M.A.(1992).An approach to the internal parasitic infections in disease freshwater fishes. M.V.Sc. Thesis, Fac. Vet. Med. Cairo Univ.

- Azevedo, T.M.P.; Martins, M.L.; Bozzo, F.R. and Moraes, F.R. (2006). Haematological and gills response in parasitized tilapia from valley of Tijucas river, SC, Brazil. Scientia Agricola, Piracicaba, 63: 115-120.

- Babiker, A.O. (2013): Comparative assessment of parasites infestation of tilapia and clarias under natural and cultured environments in khartoum state.thesis of master of science in fish technology. University of Juba, Khartoum, Sudan.

- Badran, A. F.; Aly, S. A. M. And Abd El-Aal, A. A. (1996). Studies on skin parasitic diseases of hybrid Tilapia. Assiut, Vet. Med. J. Vol. 35, No. 70., July, 1996.

- Bassiony, S. H. (2002). An approach to the internal parasitic infections in diseased freshwater fishes. M.V.Sc. Thesis, Fac. Vet. Med. Cairo Univ.

- Blanchard,R. (1885): Sur uninfusoire peritriche ectoparasite des Poissonsd'eaudouce.Bull Soc. Zool. 10:277-280. 
- Carleton, M.; Drury, Y.; Wallington, E. and Cameray, H. (1967): Carleton's Histological Technique. $4^{\text {th }}$. Ed. Oxford Univ., Press. New York, Toronto.

- Coles, E. H. (1974): Veterinary Clinical Pathology. W. B. Saunders Company, Philadelphia, London, Toronto. PP. 211-213.

- Coles, E. H. (1986). Veterinary clinical pathology. $2^{\text {nd }}$ Ed. W. B. Saunders Company, Phildelphia and London.

- De Pádua, SB, Jerônimo, GT, Ishikawa, MM, Belo, MAA, Martins, ML, Pelisari, T, Kasai, RYD \& Carrijo-Mauad, JR.( 2014): Parasitological assessment and host-parasite relationship in farmed cachara catfish fingerlings. Mato Grosso do Sul, Brazil. Neotropical Helminthology, vol. 8, n1, jan-jun, pp. 37 - 45.

- Doumas, B. T. and Biggs, H. G. (1972): Determination of serum globulin. In Standard Methods of Clinical Chemistry. Vol. 7. New York, Academic press.

- Eissa, I.A.M. (2002). Parasitic Fish Diseases in Egypt, 1st edition, pp: 52-53. Dar El-Nahdda El-Arabia Publishing, Cairo, Egypt

- El-Khatib, N.R.H. (1993). Further studies on ectoparasitic infestation in fresh water fishes. Ph. D. Thesis, Fac. Vet. Med. Cairo University.

- El-Khatib, N.R.H. (2003). "Some studies on eye affections in Oreochromis niloticus in Egypt". Vet. Med. J., Giza, 49, 1, pp. 43-55.

- El-Moghazy, D.D. (2008). Experimentally induced infections of European eel Anguilla with Anguillicola crassus (Nematoda, Dracunculoidea) and subsequent migration of larvae. Diseases of Aquatic Organisms 7, 97-101. 
- El-Sayed, E. (1993). Some studies on protozoal infection among cultured fish in Sharkia. M.V.Sc. Thesis, Zagazig University.

- El-Seify, M. A.; Abu El-Wafa, S. A.; Mahmoud, N. A. And Abd El Aal, A. M. (2003). Electron microcope study of some fish tissue protozoa in Egypt. Kafr El-Sheikh Vet. Med. J. 1: 201 - 218.

- El-Tantawy, S.A.M. and El-Sherbiny, H.A.E. (2010a): Ectoparasitic Trichodinians infecting Catfish Clariasgariepinus inhabiting Nile Delta water of the river Nile, Dakahlia Province, Egypt. Journal of American Science; 6(9):656-668.

- El-Tantawy, S.A.M. and El-Sherbiny, H.A.E. (2010b): Some Protozoan Parasites infecting Catfish Clariasgariepinus inhabiting Nile Delta water of The River Nile ,Dakahlia Province ,Egypt.Journal of American Science ,6(9):676-696.

- FAO (2013): Corporate Document Respositry Parasites,infections and diseases of fishes in Africa,Plates 8-11,12d (PP.52-57).

- Faure-Fermiet, E. (1905): Sur 1,organization de la Campanella umbellaria. Compt. Rend.58-215.

- Floyed, R.F (2003). Introduction to fish health management. Department of fisheries and aquatic sciences, Florida Cooperative extension service, Institute of food and agricultural sciences, University of Florida, circular 921.

- GAFRD "General Authority for Fish Resources Development" (2012). Fishary Statistics. Egyptian Ministry of Agriculture Book.

- Hassan, M.A. (1992). Studies on some parasitic affections in freshwater fishes in Benisuef governorate. Ph. D. Thesis, Fac. Vet. Med. Beni-Suef. Cairo Univ. 
- Hetrick, F.M. (1983): Workshop on fish diseases. Depart. Microbiol. Unv. Maryland, college Park, M. D., USA, PP: 140.

- Hines, R.S., Spira, D.T.: Ichthyophthiriasis in the mirror carp. II. Leukocyte response. J. Fish Biol., 1973; 5: 527-534.

- Hoffman, J. (1987). Parasites of North American fresh water fishes.Univ. Califorina Press, Berkeley Collage, USA. Pp. 486.

- Ibtsam, E.B.E.D. (2004). Studies on some prevailing disaeses among cultured Tilapia fish. Ph.D. Theis. Fac. Vet. Med. Suez Canal University.

- Innes, W.T. (1966). Exotic Aquarium Fishes, 9th edition. Aquarium Incorporated, New Jersey

- Jerônimo, G.T.; Speck, G.M.; Cechinel, M.M.; Gonçalves, E.L. and Martins, M.L. (2011). Seasonal variation on the ectoparasitic communities of Nile tilapia cultured in three regions in southern Brazil. Braz J Biol. 2011 May;71(2).365-73.

- Kabata, Z. (1985). Parasites and diseases of fish culture in the tropics. Printed in Great Britain by Taylor and Franks (Ltd Basingstoke Hants). Pp 127 - 161.

- Kawahara, E.; T. Ueda and S. Nomura (1991): In vitro phagocytic activity of white spotted shark cells after injection with Aeromonas salmonicida extracelluar products. Gyobyo Kenkyu, Japan, 26(4): 213-214.

- Khalil,B. (2010):Histopathology of skin of some fishes of family Sciaenidae from Karchi Coast,Thesis Submitted for Fulfilment of the Requirment of the degree of Doctor of philosophy in Zoology,Jinnah University. 
- Kind, P.R.N. and King, E.J. (1954): Estimation of plasma phosphatase by determination of hydrolyzed phenol with amino antipyrine . J. Clin. Pathol., 7(4):322-326.

- Kollner, B., Fischer, U., Rombout, J.H.W.M., Taverne-Thielec, J.J., Hansen, J.D.: Potential involvement of rainbow trout thrombocytes in immune functions: a study using a panel of monoclonal antibodies and RT-PCR. Dev. Comp. Immunol.,2004; 28: 1049-1062.

- Limit, H. S (1991). Fish pathology in Malaysia. Paper presented at the regional seminar on Ecology and conservation of south East Asian marine and fresh water environment including wetlands. Institute for advanced studied University. of Malaya. 4-6. Nov 1991.

- Liu, Y. J. and Lu, C. P. (2004). Role of Ichthyophthirius multifiliis, in the Infection of Aeromonas hydrophila. J Vet Med B Infect Dis Vet Public Health. 2004 Jun; 51(5): 222-4.

- Lucky, Z. (1977). Methods for the diagnosis of fish diseases. Amerind Publishing Co., Pvt. Ltd. New Delhi, Bombay Calcutta and New York.

- Mahfouz, N.B.M. (1997). Effect of parasitism on immunity in cultured freshwater fish. Ph.D. Thesis. Fac. Vet. Med. Tanta University.

- Marzouk M.S. (2002): Selected Notes No fish disease and Management, Cairo University of Vet Medicine.

- Mohamed, I. (1996). Pathological changes in some fish eating mammals as a result of consumption of improperly cooked fishes. $\mathrm{Ph}$. D. Thesis (Pathology), Fac. Vet. Med. Cairo University. 
- Mohamed, M.A.; Ezz El Dien and Elsayed, E. E. (2004). Tissue protozoa (Myxobolus dermatobia) from the eye in Tilapia zilli in Egypt. $1^{\text {st }}$ inter Conf. Vet. Res. Div. NRC, Cairo, Egypt, pp. 307 319.

- Murad, A. and Mostafa, S. (1988). Blood parameters of catfish, Heteropneustes fassilis (Bloch) parasitized by metacercaria of Diplostomum species. J. Fish Dis., 11: 365 - 368.

- Noor El-Deen, A.I.; Abd El Hady and Kenawy, A.M. (2014): Comparative Studies on Some Prevailing Parasitic Diseases Cultured Freshwater Fingerlings and Adult Oreochromis niloticus on Some Fish Farms.Life Science Journal ;11(10).

- Osman, M.A.H. (2001). Studies on parasitic gill affections in some cultured freshwater fishes. M.V.Sc. Thesis, Fac. Vet. Med. Suez Canal Univ.

- Osman, M.A.H. (2005). studies on Monogenasis among fishes. Thesis Ph. D. Thesis fac. Vet. Med. Suez Canal Univ.

- Otify, Y. Z; A. A, EL-Sawak and M. K, Solomon (1991). Parasitological and pathological studies on skin and gills affections in tilapia species. Beni-Suef. Vet. Med. Res. Vol. 1.

- Paperna, I. (1996). Parasites infection \& diseases of fish. Book 6.in.S.F.Sneiszko and H.R. Axelord eds. Diseases of fishes. T.F.A. Publications Inc. Ltd.

- Paperna, I. and Van, J. G. (1983). The pathology of Chilodenella hexasticha (Kiernik) infection in Cichlid fishes. J. Fish. Biol. 23: 441 -450 . 
- Peters, T. Jr. (1970): Serum albumin. Adv. Clin. Chem., 13:37-111.

- Rashed, D.T. (2007). Some studies on helminthes parasites of fresh water in Egypt. Alex. J. Vet. Sci., 4(1). 357-367.

- Rashed, M.A.M. (2013): Studies On Some Parasitic Diseases On The Gills of Some Freshwater Fishes.Ph.D. Thesis,Faculty of Vet. Med., Kafrelsheik Univ.

- Rawia Adawy, S.M. (2000). Studies on the parasitic dieases of some freshwater fishes in Dakahlia Governorate. Ph. D. Thesis, Fac. Vet. Med., Cairo Univ.

- Reitman, S. and Frankle, S. (1957): A colorimetric method for the determination of serum glutamic oxalacetic and glutamic pyruvic transminases. Amer. J. Clin. Path., 28:56-63.

- Roberts, R. J. (1978): Fish Pathology. Bailliere, Tindall, London.

- Roberts, R.J. (2012): Fish pathology. $4^{\text {th }}$ edition published by blackwell, Puplishing Ltd.,UK.

- Saad, N. (2008): (Lernaidae) as carp parasitic infestation in summer. Cairo Vet. Med. J. Vol.2, No.4,261_266.

- Saleh, G. Aly and El-Nobi, G. Ahmed (2003). Prevalence of Monogeniasis in Tilapia fish among different systems of fish management, seasons and fish life stages with special reference to the therapeutic effect of Praziquantel at different temperatures. Zag.Vet.J. (ISSN.1110-1458)Vol. 31, No.1, pp. 37-48.

- Schalm,O. W. (1986): Veterinary hematology. $4^{\text {th }}$ Ed., Lea and Febiger, Philadelphia. 
- Stoskopf, K. M. (1993). Fish Medicine. W. B. Saunders Compony, Harcourt Brace Jovanovich, Inc.

- Tavares-Dias, M., de Morales, F.R., Martins, M.L., Santana, A.E. (2002): Haematological changes in Oreochromis niloticus (Osteichthyes: Cichlidae) with gill ichthyophthiriasis and saprolegniosis. Bol.Inst. Pesca, Sao Paulo, 28: 1-9.

- Tavares-Dias, M., Ono, E.A., Pilarski, F., Moraes, F.R. (2007): Can thrombocytes participate in the removal of cellular debris in the blood circulation of teleost fish? A cytochemical study and ultrastructural analysis. J. Appl. Ichthyol. 23: 709-712.

- Tawfik, M.A.A. (2005). Studies on some fish-borne trematodes in Egypt. J. Vet. Sci. Vol. 43, pp. $49-58$.

- Woo, P.T.K. (1995). Fish diseases and disorders. CAB, Int. Wallingford, Oxon, UK.

- Yatabe, T.; Arriagada, G.; Hamilton-West, C. and Urcelay, S. (2011). Risk factor analysis for sea lice, Caligus rogercresseyi, levels in farmed salmonids in southern Chile. J Fish Dis. 2011 May;34(5).345-54.

- Younis, A. A. E. (1999). Effect of some ecarasites on the blood and serum constituents of Oreochromis niloticus fish with referring to treatment. Benisuef. Vet. Med. J. Vol. 9, No. 3, 341 - 351. 
بعض الدراسات على أمر اض الأوليات الهدبية فى أسماك المياه العذبة بمحافظة كفر الثنيخ

في هذه الدراسة نم فحص 1600 سمكة مياة عذبة من انواع البلطي النيلي ، القرموط الافريقي ، المبروك العادي والبوري ، 100 سكة من كل نوع في كل فصل من فصول السنة ، مختلفة الاحجام والاوزان ، وذلك لاستبيان الامراض الثائعة التي نسبيها الأوليات الهدبية ، حيث تم عزل وتصنيف طفيليات التزيكودينا ، الكيلودينلا،الاكثيوفنثيريس ملتيفلس ، الابيزوما والابستيلس،ونسب حدوثها فصليا. تم تسجيل الاعراض الخارجية والافات التشريحية للاسماك المريضة ـايضا نم اجراء بعض الفحوص الدموية والبيوكيميائية للاسماك المصابة وتسجيل نتائجها ، نم دراسة وتسجيل بعض التغيرات النسجية علي جلد وخياشيم وزعانف الاسماك المصابة طبيعيا بالاوليات الهدبية. 